\title{
Influence of Cabbage (Brassica oleracea) Accession and Growing Conditions on Myrosinase Activity, Glucosinolates and Their Hydrolysis Products
}

\author{
Omobolanle O. Oloyede *(D), Carol Wagstaff $(\mathbb{D}$ and Lisa Methven $(\mathbb{D}$ \\ Department of Food and Nutritional Sciences, Harry Nursten Building, University of Reading, Whiteknights, \\ Reading RG6 6DZ, UK; c.wagstaff@reading.ac.uk (C.W.); 1.methven@reading.ac.uk (L.M.) \\ * Correspondence: bola.oloyede@reading.ac.uk; Tel.: +44-(0)118-378-3606
}

check for updates

Citation: Oloyede, O.O.; Wagstaff, C.; Methven, L. Influence of Cabbage (Brassica oleracea) Accession and Growing Conditions on Myrosinase Activity, Glucosinolates and Their Hydrolysis Products. Foods 2021, 10, 2903. https://doi.org/10.3390/ foods10122903

Academic Editors: Franziska S. Hanschen and Sascha Rohn

Received: 11 October 2021

Accepted: 18 November 2021

Published: 23 November 2021

Publisher's Note: MDPI stays neutral with regard to jurisdictional claims in published maps and institutional affiliations.

Copyright: (c) 2021 by the authors. Licensee MDPI, Basel, Switzerland. This article is an open access article distributed under the terms and conditions of the Creative Commons Attribution (CC BY) license (https:// creativecommons.org/licenses/by/ $4.0 /)$.

\begin{abstract}
Glucosinolates are secondary plant metabolites present in Brassica vegetables. The endogenous enzyme myrosinase is responsible for the hydrolysis of glucosinolates, yielding a variety of compounds, including health-promoting isothiocyanates. The influence of cabbage accession and growing conditions on myrosinase activity, glucosinolates (GSL) and their hydrolysis products (GHPs) of 18 gene-bank cabbage accessions was studied. Growing conditions, cabbage morphotype and accession all significantly affected myrosinase activity and concentration of glucosinolates and their hydrolysis products. In general, cabbages grown in the field with lower growth temperatures had significantly higher myrosinase activity than glasshouse samples. Profile and concentration of glucosinolates and their hydrolysis products differed across the accessions studied. Aliphatic glucosinolates accounted for more than $60 \%$ of total glucosinolates in most of the samples assessed. Nitriles and epithionitriles were the most abundant hydrolysis products formed. The results obtained showed that consumption of raw cabbages might reduce the amount of beneficial hydrolysis products available to the consumer, as more nitriles were produced from hydrolysis compared to beneficial isothiocyanates. However, red and white cabbages contained high concentrations of glucoraphanin and its isothiocyanate, sulforaphane. This implies that careful selection of accessions with ample concentrations of certain glucosinolates can improve the health benefits derived from raw cabbage consumption.
\end{abstract}

Keywords: Brassica oleracea; cabbage; growing condition; myrosinase activity; glucosinolates; glucosinolate hydrolysis products; isothiocyanates; nitriles; epithionitriles

\section{Introduction}

Cabbage (Brassica oleracea) belongs to the Brassicaceae family and comprises eight distinct cultivar groups, all descended from wild cabbage (B. oleracea var. oleracea) [1] Epidemiological studies have shown that the consumption of Brassica vegetables reduces the risks of cardiovascular diseases and cancer [2] and is reported to have a cytoprotective effect against tissue damage associated with oxidative stress as well as antimicrobial activity against bacterial and fungal pathogens $[3,4]$.

Brassica vegetables are unique in comparison to other vegetables because they contain the enzyme myrosinase and a group of thioglucosides called glucosinolates (GSLs). GSLs are sulphur and nitrogen containing biologically active secondary metabolites found in plants of the order Capparales, which includes the Brassicaceae family and other economically important agricultural crops [5-7]. In plants, GSLs act as plant defense mechanisms against stress, insect, and pest attack [8]. GSLs have been grouped into three main classes based on the structure of their different amino acid precursors; these groups are aliphatic, aromatic and indole GSLs. Aliphatic GSLs are derived from alanine, leucine, isoleucine, methionine or valine; aromatic GSLs are from phenylalanine or tyrosine, while tryptophan- 
derived GSLs are called indole GSLs [9,10]. A recent review by Blažević et al. [11] stated that between 88-137 glucosinolates (GSLs) have been characterised in plants to date.

GSLs and myrosinase enzymes coexist in separate compartments in the plants; while glucosinolates exists in the vacuoles of various cells [6], myrosinase enzymes are localised inside the myrosin cells. When plant tissue is disrupted, GSLs are hydrolysed by plant myrosinase enzymes, resulting in the formation of various hydrolysis products such as isothiocyanates (ITCs), thiocyanates, nitriles and epithionitriles [5]. The extent of glucosinolate hydrolysis and the type of hydrolysis compound produced is dependent on a number of factors, which include coexisting myrosinase enzyme, presence of epithiospecifier protein (ESP), ascorbic acid, $\mathrm{Fe}^{2+}$ and $\mathrm{MgCl}_{2}$, structure of the glucosinolate side chain, the plant species, as well as reaction conditions such as $\mathrm{pH}$ and temperature $[9,12,13]$.

ITCs, the primary products of GSL hydrolysis from myrosinase, are responsible for the well-documented health-promoting properties of Brassica vegetables, such as reduced risk of cardiovascular diseases (CVD) and cancer [2,5]. For example, sulforaphane (SFP), the hydrolysis product of glucoraphanin present in high concentrations in broccoli and cabbage, has been reported to possess chemoprotective, antimicrobial, anti-inflammatory, and antithrombotic properties [14,15]. Allyl isothiocyanate (AITC), another common ITC present in cabbages and produced upon myrosinase hydrolyses of the glucosinolate sinigrin (SIN), was reported to be potent against human breast cancer cells [16], human erythroleukemic K562 cells [17], and more potent on human A549 and H1299 non-small cell lung cancer cells in vitro than 2-phenylethyl-ITC (PEITC; ITC from gluconasturtin) [18]. However, in the presence of epithiospecifier proteins (ESPs), nitriles and epithionitriles (EPTs), which have not been shown to proffer any beneficial characteristics for health, are formed [19]. GSLs and ITCs are also partly responsible for the bitter taste and pungent aromas of Brassica vegetables, which limits consumer acceptance and liking of Brassica vegetables [20-23].

There are several factors that affect the GSL-myrosinase system in Brassicas; these factors include climatic factors, location, and growing conditions [24-27], morphotype and the variety of plant [28,29]; with the impact of these factors varying between studies. For example, while some authors have suggested that the effect of plant genotype on GSL concentrations is greater than that of environmental factors [30,31], others have reported higher variations in GSL concentrations as a result of environmental conditions than genetic factors [32,33].

To date, most studies on myrosinase activity have focused on single cultivars of B. oleracea species [28,34-37], with studies on the myrosinase activity of different varieties within a species limited $[29,38]$. Variations in myrosinase activities were reported in different varieties of Brussels sprouts, broccoli, cauliflower, Chinese cabbage, and white cabbage [38]. The authors found a two-fold difference in the myrosinase activities of five broccoli varieties as well as two cauliflower and Chinese cabbage varieties. Low temperature conditions are reported to increase the myrosinase activity of $B$. oleracea species (Brussels sprout, broccoli, cauliflower, cabbage, and kale) grown in the autumn season [25].

Several studies have been undertaken on the formation of GSLs in cabbage varieties, some of which have investigated GSL concentrations in cabbages grown under different conditions; with , most focused on GSL concentrations of cabbages grown in different locations or different seasons [29,32,39-41]. However, none of the studies analysed the glucosinolate hydrolysis products (GHPs) of cabbages under different plant growth conditions and instead made suggestions on potential GHP concentrations of the samples based on the concentrations of GSLs observed. These suggestions may be problematic, as studies have shown that GSL concentration is not necessarily correlated with the abundance of GHPs formed [42,43].

Little is known of the GHPs in cabbages, as most studies have focused on a specific cabbage variety [44] or ITCs in other B. oleracea such as broccoli [45]. A recent study analysed the GSLs and GHPs of cabbages with a focus on red, white and savoy cabbages, but the samples were grown under the same conditions [43]. To fully understand the 
health benefits that can be derived from cabbage consumption, however, there is a need to characterize the GHPs produced from GSL hydrolysis and understand the factors affecting the type and concentrations of GHPs formed. With growing health campaigns promoting the consumption of more fruits and vegetables, and consumers wanting to include more fresh vegetables like cabbage in their diet, many people now grow their own cabbages at home in pots, either in green/glasshouses or in the garden [46,47]. It is therefore important to investigate the effect of these plant growth conditions on the GSL-myrosinase system to ensure that the health benefits desired from their consumption are not lost.

In light of this gap in present knowledge, the purpose of this study was to investigate the influence of growing conditions and accession identity on myrosinase activity as well as the GSL and GHP content of cabbage. A total of 18 cabbage accessions across six different cabbage morphotypes were selected from a genetic resources unit and grown under two different conditions. In addition to wild cabbage, this study used red, white, and green (savoy) cabbage (B. oleracea var. capitata), kale (B. oleracea var. acephala) and sea kale (B. oleracea var. tronchuda). The primary hypothesis of the study was that cabbage growth conditions will affect myrosinase activity as well as the GSL and GHP contents of cabbage. The secondary hypothesis was that while cabbage morphotype and accession would affect myrosinase activity, cabbage morphotype rather than accession will affect the profile and concentrations of the GSLs and GHPs formed. The results of myrosinase activity and variations in the amount and profile of GSLs and GHPs in cabbage accessions across both plant conditions studied are presented.

\section{Materials and Methods}

\subsection{Plant Material}

Cabbage accessions were selected from the University of Warwick Crop Centre Genetic Resources Unit (Wellesbourne, UK). Eighteen cabbage accessions comprising six cabbage morphotypes (wild (B. oleracea var. oleracea), black kale (B. oleracea var. acephala), tronchuda (B. oleracea var. tronchuda), savoy, red and white (B. oleracea var. capitata)) were used for the experiment. Cabbages were selected based on their geographical origin, whether or not they were of hybrid descent, and morphology of head formation (closed heart or open leaf), as shown in Table 1 and Supplementary Figure S1. Seeds of one white cabbage accession (WC-DLI) did not germinate when sown and thus will not be discussed further. Out of the remaining 17 accessions planted, RC-RM (red cabbage) and SC-SDG (savoy cabbage) did not survive in the glasshouse.

A total of 15 biological replicates of each accession were germinated in seedling trays using potting compost under controlled environmental conditions (Saxcil cabinets). A $16 \mathrm{~h}$ photo period was used ( $16 \mathrm{~h}$ light, $8 \mathrm{~h}$ dark); relative humidity was set to $60 \%$, with day and night temperatures of $22^{\circ} \mathrm{C}$ and $16^{\circ} \mathrm{C}$, respectively. Seedlings were allowed to grow in seedling trays until the appearance of 3-4 true leaves, before being transplanted to individual 2.5 L pots containing loam-based compost (7-8 May 2014) and left to grow in the glasshouse (minimum night temperature $13^{\circ} \mathrm{C}$ ). After 50 days (26-27 June 2014), five replicates of each accession were transplanted to larger pots $(10 \mathrm{~L})$ containing loam-based compost and allowed to grow until commercial maturity in the glasshouse, while seven replicates of each accession were transplanted to the field and allowed to grow to commercial maturity. On the field, each accession was planted on 7 metre beds with 0.6 metres between plants and rows. Both glasshouse and field cabbages were fertilized twice weekly with nitrogen phosphate potassium (NPK) $(100 \mathrm{~kg} / \mathrm{ha} \mathrm{N}, 100 \mathrm{~kg} / \mathrm{ha} \mathrm{P}$ and $200 \mathrm{~kg} / \mathrm{ha} \mathrm{K})$ fertilizer. Standard agricultural practices were employed in the cultivation of the cabbages, including a programme of pest management using insecticides and fungicides. Cabbages were grown between 7 March-25 November 2014 in the plant growth facilities, Whiteknights campus of the University of Reading, UK (Supplementary Figure S2). 
Table 1. Origin and botanical and common names of cabbage accessions planted between May and November 2015.

\begin{tabular}{|c|c|c|c|c|c|}
\hline Genus/Morphotype ${ }^{a}$ & Accession Name & Accession Code & Common Name & Origin & Head Formation \\
\hline \multicolumn{6}{|l|}{ Black kale } \\
\hline Brassica oleracea var. acephala & Cavolo nero di toscana o senza palla & BK-CNDTP (BK1) & Fodder black kale & Italy & Open leaf \\
\hline Brassica oleracea var. acephala & Cavolo palmizio & $\mathrm{BK}-\mathrm{CPNT}(\mathrm{BK} 2)$ & Black kale & Italy & Open leaf \\
\hline Brassica oleracea var. acephala & Cavolo nero di toscana o senza testa & BK-CNDTT (BK3) & Fodder black kale & Italy & Open leaf \\
\hline \multicolumn{6}{|l|}{ Wild } \\
\hline Brassica oleracea var. oleracea & Wild cabbage & WD-8707 (WD1) & Wild cabbage & Great Britain & Open leaf \\
\hline Brassica oleracea var. oleracea & Wild cabbage & WD-GRU (WD2) & Wild cabbage & New Zealand & Open leaf \\
\hline Brassica oleracea var. oleracea & Wild cabbage & WD-8714 (WD3) & Wild cabbage & Great Britain & Open leaf \\
\hline \multicolumn{6}{|l|}{ Tronchuda } \\
\hline Brassica oleracea var. tronchuda & Penca mistura & TC-PCM (TC1) & Tronchuda cabbage & Portugal & Open leaf \\
\hline Brassica oleracea var. tronchuda & Penca povoa & TC-CPDP (TC2) & Tronchuda cabbage & Portugal & Open leaf \\
\hline Brassica oleracea var. tronchuda & Tronchuda & TC-T (TC3) & Tronchuda cabbage & Portugal & Open leaf \\
\hline \multicolumn{6}{|l|}{ Savoy } \\
\hline Brassica oleracea var. capitata & Hybrid savoy wirosa cabbage & SC-HSC (SC1) & Hybrid savoy cabbage & Great Britain & Closed heart \\
\hline Brassica oleracea var. capitata & Pointed winter & SC-PW (SC2) & Savoy cabbage & Great Britain & Closed heart \\
\hline Brassica oleracea var. capitata & Dark green & SC-SDG (SC3) & Savoy cabbage & Italy & Closed heart \\
\hline \multicolumn{6}{|l|}{ Red } \\
\hline Brassica oleracea var. capitata & Red langendijker & RC-RL (RC1) & Red cabbage & Great Britain & Closed heart \\
\hline \multicolumn{6}{|l|}{ White } \\
\hline Brassica oleracea var. capitata & Early market & WC-FEM (WC1) & White spring cabbage & Great Britain & Closed heart \\
\hline Brassica oleracea var. capitata & Couve repolho & WC-CRB (WC2) & White cabbage & Portugal & Closed heart \\
\hline Brassica oleracea var. capitata & De louviers & WC-DLI (WC3) & Hybrid white cabbage & Great Britain & Closed heart \\
\hline
\end{tabular}


Cabbages were harvested over a period of two days upon reaching commercial maturity based on visual inspection. Though some accessions attained commercial maturity earlier than others, they had sufficiently good field holding capacity to be left until all accessions were mature before harvesting, so that all plants experienced equivalent environmental conditions. Harvested plants were placed on ice in freezer bags and immediately stored in a cold room at $4{ }^{\circ} \mathrm{C}$ for $24 \mathrm{~h}$ before processing. The average weight of each field cabbage head per plant was $700 \mathrm{~g}$ (closed heart) and $300 \mathrm{~g}$ (open leaf), while the glasshouse cabbages were smaller (400 $\mathrm{g}$ for closed heart and $250 \mathrm{~g}$ for open leaf cabbages) (Supplementary Figure S1). Climatic data for both growing conditions are presented in Supplementary Table S1.

\subsection{Reagents and Chemicals}

Sinigrin standard was purchased from Santa Cruz Biotechnology (Heidelberg, Germany) and D-glucose determination kit was from R-Biopharm Rhone (Heidelberg, Germany). All other chemicals used were purchased from Sigma-Aldrich (Dorset, UK).

\subsection{Sample Preparation}

The outer leaves and central core of 4-5 cabbage heads (biological replicates) were removed and discarded in order to remove senescent leaves and achieve a representative sample spanning similar leaf ages for each morphotype. Cabbages were chopped into pieces of approximately $1 \mathrm{~cm}$ in width using a kitchen knife (representing how cabbages would normally be sliced by consumers), mixed together, and washed under running tap water; excess water was drained using a salad spinner (OXO Good Grips Clear Manual Salad Spinner, Chambersburg, PA, USA). A total of $120 \mathrm{~g}$ of cabbage samples was put into sterile sterilin tubes, immediately placed on ice, and transferred to a $-80^{\circ} \mathrm{C}$ freezer. Frozen samples were freeze-dried (Stokes freeze drier, Philadelphia, PA, USA), ground using a tissue grinder (Thomas Wiley ${ }^{\circledR}$ Mini-Mill, Thomas Scientific, Swedesboro, NJ, USA) and stored at $-20^{\circ} \mathrm{C}$ until further analysis.

\subsection{Myrosinase Enzyme Extraction and Assay}

Myrosinase enzyme was extracted using the method described by Ghawi et al. [48]. A sample of $0.1 \mathrm{~g}$ was suspended in $0.15 \mathrm{~g}$ polyvinylpolypyrrolidone (PVPP) and $10 \mathrm{~mL}$ of Tris-HCL buffer (200 mM, pH 7.5) containing $0.5 \mathrm{mM}$ ethylenediaminetetracetic acid (EDTA) and $1.5 \mathrm{mM}$ dithiothreitol (DTT). The mixture was stirred for $15 \mathrm{~min}$ at $5{ }^{\circ} \mathrm{C}$ and centrifuged $(11,738 \times g)$ for $15 \mathrm{~min}$ at $5^{\circ} \mathrm{C}$. The final volume of supernatant was made up to $10 \mathrm{~mL}$ using the Tris-HCL buffer. Then, $6.2 \mathrm{~g}$ ammonium sulphate was added to the supernatant to achieve $90 \%$ saturation and stirred at $5{ }^{\circ} \mathrm{C}$ for $30 \mathrm{~min}$. The samples were then centrifuged $(13,694 \times g)$ for $15 \mathrm{~min}$ at $5^{\circ} \mathrm{C}$. The resulting pellet was suspended in $2 \mathrm{~mL}$ Tris- $\mathrm{HCl}$ buffer $(10 \mathrm{mM}, \mathrm{pH} 7.5)$ and assayed for myrosinase activity.

Myrosinase activity was measured using the coupled enzyme method described by Gatfield and Sand [49] and Wilkinson et al. [50], with slight modifications. The procedure depends on the glucose released from the reaction between myrosinase enzymes and the substrate (sinigrin). The mixture for the reaction consisted of $0.9 \mathrm{~mL}$ of $5 \mathrm{mM}$ ascorbic acid, $0.5 \mathrm{~mL}$ ATP/NADP+ solution, $10 \mu \mathrm{L}$ hexokinase/glucose-6-phosphate dehydrogenase and $50 \mu \mathrm{L}$ crude enzyme extract. The mixture was homogenized and allowed to stand for $3 \mathrm{~min}$, and then $50 \mu \mathrm{L}$ sinigrin substrate $(0.6 \mathrm{M})$ added. The change in absorbance due to NADPH formation was read on a spectrophotometer at $340 \mathrm{~nm}$. Myrosinase enzyme activity was determined by taking the slope of the linear part of the curve of absorbance versus the time of reaction. One unit of myrosinase activity is defined as the amount of enzyme that produces $1 \mu \mathrm{mol}$ of glucose from sinigrin substrate per minute at $\mathrm{pH}$ 7.5.

\subsection{Protein Assay}

Protein content was measured using the Bradford method [51]. The procedure is based on formation of a complex between dye (brilliant Blue G, Sigma-Aldrich, Dorset, UK) 
and the protein present in the sample, and absorbance is read at $595 \mathrm{~nm}$ using a spectrophotometer. $50 \mu \mathrm{L}$ filtered crude enzyme extract was added to $1.5 \mathrm{~mL}$ of concentrated dye reagent, vortexed and allowed to stand for $20 \mathrm{~min}$ before taking the absorbance reading. Bovine serum albumin (BSA) (Sigma-Aldrich, Dorset, UK) was used to construct a standard curve, and the protein concentration of sample was calculated from the standard curve obtained. Protein content was used to calculate the specific activity of myrosinase enzymes (U/mg protein).

\subsection{Glucosinolate Extraction and LC-MS ${ }^{2}$ Analysis}

The method used for GSL extraction is as described by Bell et al. [52], with modifications. Briefly, $40 \mathrm{mg}$ ground cabbage powder was heated in a heat block at $75{ }^{\circ} \mathrm{C}$ for two minutes. Then, $1 \mathrm{~mL} 70 \%(\mathrm{v} / \mathrm{v})$ methanol preheated to $70{ }^{\circ} \mathrm{C}$ was added to each sample, vortexed and placed in a preheated $\left(70^{\circ} \mathrm{C}\right)$ water bath for $20 \mathrm{~min}$. Samples were centrifuged at full speed for five minutes $\left(18{ }^{\circ} \mathrm{C}\right)$, and supernatant was collected in fresh Eppendorf tubes. The volume was adjusted to $1 \mathrm{~mL}$ with $70 \%(v / v)$ methanol and frozen at $-80^{\circ} \mathrm{C}$ until further analysis.

Samples were filtered using $0.22 \mu \mathrm{m}$ Millex syringe filters with a low protein binding Durapore polyvinylidene fluoride (PVDF) membrane (Fisher scientific, Loughborough, UK) and diluted with $9 \mathrm{~mL}$ HPLC-grade water. LC-MS analysis of GSL extracts was performed in negative ion mode on an Agilent 1200 Series LC system (Agilent, Stockport, UK) equipped with a variable wavelength detector and coupled to a Bruker HCT ion trap (Bruker, Coventry, UK). Sample separation was achieved on a Gemini $3 \mu \mathrm{m} \mathrm{C}_{18} 110 \AA$ $(150 \times 4.6 \mathrm{~mm})$ column (with Security Guard column, $\mathrm{C}_{18} ; 4 \mathrm{~mm} \times 3 \mathrm{~mm}$; Phenomenex, Macclesfield, UK). GSLs were separated during a $40 \mathrm{~min}$ chromatographic run, with a 5 min post-run sequence. Mobile phases consisted of $95 \%$ of $0.1 \%$ ammonium formate solution and $5 \%$ acetonitrile. The flow rate was optimised for the system at $0.4 \mathrm{~mL} / \mathrm{min}$, with a column temperature of $30^{\circ} \mathrm{C}$ and with $5 \mu$ of sample injected into the system. GSLs were quantified at a wavelength of $229 \mathrm{~nm}$.

MS analysis settings were as follows: electrospray ionization (ESI) was carried out at atmospheric pressure in negative ion mode (scan range m/z 100-1500 Da). Nebulizer pressure was set at $50 \mathrm{psi}$, gas-drying temperature at $350{ }^{\circ} \mathrm{C}$, and capillary voltage at 2000 V. GSLs were quantified using sinigrin hydrate standard. Five concentrations of sinigrin hydrate $(14-438 \mu \mathrm{g} / \mathrm{mL})$ were prepared with $70 \%$ methanol and used to prepare an external calibration curve $\left(r^{2}=0.996\right)$. Compounds were identified using their parent mass ion and characteristic ion fragments as well as comparing with literature ion data (Table 2). Compounds were quantified using Bruker Daltonics HyStar software (Bruker, Coventry, UK). Relative response factors (RRFs) were used in the calculation of GSL concentrations where available [53]. Where such data could not be found for intact GSLs, RRFs were assumed to be 1.0.

Table 2. Intact glucosinolates identified in cabbage accessions analysed by LC-MS.

\begin{tabular}{|c|c|c|c|c|c|}
\hline Common Name & Chemical Name & Abbreviation & Mass Parent Ion & $\mathrm{MS}^{2}$ Spectrum Ion (Base Ion in Bold) ${ }^{a}$ & Reference \\
\hline sinigrin & 2-propenyl(allyl) GSL & SIN & 358 & $278,275,259,227,195,180,162$ & {$[54,55]$} \\
\hline gluconapin & 3-butenyl GSL & GPN & 372 & $292,275,259,195,194,176$ & {$[54,56]$} \\
\hline epi/progoitrin & (R, S)-2-hydroxy-3-butenyl GSL & PROG & 388 & $332,308,301,275,259,210,195,146,136$ & {$[54-56]$} \\
\hline glucoiberverin & 3-(methylthio)propyl GSL & GIBVN & 406 & $326,275,259,288,228,195$ & {$[52,54,55]$} \\
\hline glucoerucin & 4-(methylthio)butyl GSL & GER & 420 & $340,291,275,259,227,195,178,163$ & {$[52,54,55]$} \\
\hline glucoiberin & 3-(methylsulfinyl) propyl GSL & GIBN & 422 & $407,358,259$ & {$[54-56]$} \\
\hline glucoraphanin & 4-(methylsulfinyl) butyl GSL & GRPN & 436 & $422,372,291,259,194$ & {$[52,54,55]$} \\
\hline glucobrassicin & 3-indolylmethyl GSL & GBSN & 447 & $275,259,251,205$ & {$[54-56]$} \\
\hline 4-hydroxyglucobrassicin & 4-hydroxy-3-indolylmethyl GSL & $4-\mathrm{HOH}$ & 463 & $383,285,267,259,240,195$ & [54-56] \\
\hline
\end{tabular}




\subsection{Extraction of Glucosinolate Hydrolysis Products}

GHPs were extracted and analysed following the method described by Bell et al. [57]. A total of $0.5 \mathrm{~g}$ of lyophilized cabbage was mixed with $10 \mathrm{~mL}$ deionized water, vortexed and allowed to incubate for three hours at $30^{\circ} \mathrm{C}$. The mixture was then centrifuged at $5000 \times g$ $\left(18{ }^{\circ} \mathrm{C}\right)$ for ten minutes, and the supernatant collected. The pellet was extracted two more times with $10 \mathrm{~mL}$ deionized water, and the supernatants were combined and filtered ( $0.45 \mu \mathrm{m}$ syringe filters, Epsom, UK) into glass centrifuge tubes. GHPs were extracted by adding an equal volume of dichloromethane (DCM) to the supernatant, vortexed for one minute and centrifuged at $3000 \times g$ for ten minutes. After centrifugation, the organic phase was collected, and the extraction step repeated twice. The organic phase collected was combined, $2 \mathrm{~g}$ sodium sulphate salt was added to remove any excess liquid present, and the mixture was filtered into a round-bottom flask. The filtrate was dried using a rotatory evaporator $\left(37^{\circ} \mathrm{C}\right)$, re-dissolved in $1 \mathrm{~mL}$ DCM, and filtered $(0.22 \mu \mathrm{m}$ filter; Fisher scientific, Loughborough, UK) in GC-MS glass vials (VWR, Lutterworth, UK) for GC-MC analysis.

\subsection{GC-MS Analysis}

GC-MS analysis was performed on an Agilent 7693/5975 GC-MS autosampler system (Agilent, Manchester, UK). The sample was injected onto a HP-5MS $15 \mathrm{~m}$ non-polar column DB-5MS (J and W scientific, Santa Clara, CA, USA) (0.25- $\mu \mathrm{m}$ film thickness, $0.25 \mathrm{~mm}$ I.D.). The injection temperature was $250{ }^{\circ} \mathrm{C}$ in split mode (1:20). The oven temperature was programmed from 40 to $320^{\circ} \mathrm{C}$ at a rate of $5{ }^{\circ} \mathrm{C} / \mathrm{min}$ until $250{ }^{\circ} \mathrm{C}$. The carrier gas was helium, with flow rate of $1.1 \mathrm{~mL} / \mathrm{min}$ and pressure of 7.1 psi. Mass spectra were obtained by electron ionization at $70 \mathrm{eV}$, and mass scan from 35 to $500 \mathrm{amu}$. A total of $1 \mu \mathrm{L}$ of the sample was injected, and compounds were separated during a $42 \mathrm{~min}$ run. Compounds were identified using the National Institute of Standards and Technology (NIST) library and literature ion data (Table 3; see Figure S3 for GC-MS chromatograms) and quantified based on an external standard calibration curve. Five concentrations $(0.15-0.5 \mathrm{mg} / \mathrm{mL})$ of sulforaphane standard (Sigma Aldrich, Dorset, UK) were prepared in DCM $\left(r^{2}=0.99\right)$. Data analysis was performed using ChemStation for GC-MS (Agilent, Manchester, UK). 
Table 3. Glucosinolate hydrolysis products identified in cabbage accessions analysed by GC-MS.

\begin{tabular}{|c|c|c|c|c|c|c|c|}
\hline \multirow{2}{*}{$\begin{array}{l}\text { Precursor } \\
\text { Glucosinolate }\end{array}$} & \multicolumn{2}{|c|}{ Glucosinolate Hydrolysis Product } & \multirow{2}{*}{ Abbreviation } & \multirow{2}{*}{$\mathrm{LRI}^{\mathrm{a}}$} & \multirow{2}{*}{ ID $^{b}$} & \multirow{2}{*}{$\begin{array}{l}\text { MS }^{2} \text { Spectrum Ion } \\
\text { (Base Ion in Bold) }^{c}\end{array}$} & \multirow{2}{*}{ Reference } \\
\hline & Common name & Chemical Name & & & & & \\
\hline \multirow{3}{*}{ sinigrin } & allyl thiocyanate & 2-propenyl thiocyanate & ATC & 871 & $\mathrm{~B}$ & $99,72,45,44,41,39$ & [58] \\
\hline & allyl-ITC & 2-propenyl isothiocyanate & AITC & 884 & $\mathrm{~B}$ & $99,72,71,45,41,39$ & {$[58,59]$} \\
\hline & 1-cyano-2,3-epithiopropane & 3,4-epithiobutane nitrile & CETP & 1004 & $\mathrm{~B}$ & $99,72,66,59,45,41,39$ & [58] \\
\hline \multirow[t]{2}{*}{ gluconapin } & 3-butenyl-ITC & 1-butene, 4-isothiocyanate & 3BITC & 983 & $\mathrm{~B}$ & $113,85,72,64,55,46,45,41$ & [58-60] \\
\hline & 4,5-epithiovaleronitrile & 1-cyano-3,4-epithiobutane & EVN & 1121 & B & $113,86,80,73,60,45$ & {$[60]$} \\
\hline \multirow[t]{3}{*}{ progoitrin } & goitrin & 5-vinyloxazolidin-2-thione & GN & 1545 & $\mathrm{~B}$ & $129,86,85,68,57,45,43,41,39$ & \multirow{3}{*}{ [61] } \\
\hline & $\begin{array}{l}\text { 1-cyano-2-hydroxy-3,4-epit- } \\
\text { hiobutane isomer } \\
1\end{array}$ & $\begin{array}{l}\text { 2-hydroxy-3,4-epithiobutylcyanide } \\
\text { diastereomer-1 }\end{array}$ & CHETB-1 & 1225 & $\mathrm{~B}$ & $129,111,89,84,68, \mathbf{6 1}, 58,55,45$ & \\
\hline & $\begin{array}{l}\text { 1-cyano-2-hydroxy-3,4-epit- } \\
\text { hiobutane isomer } \\
2\end{array}$ & $\begin{array}{l}\text { 2-hydroxy-3,4-epithiobutylcyanide } \\
\text { diastereomer-2 }\end{array}$ & CHETB-2 & 1245 & $\mathrm{~B}$ & $129,111,89,84,68,61,58,55,45$ & \\
\hline glucoiberverin & 4-methylthiobutyl nitrile & 4-methylthio butanenitrile & $4 \mathrm{MBN}$ & 1085 & $\mathrm{~B}$ & $115,74,68, \mathbf{6 1}, 54,47,41$ & {$[58]$} \\
\hline \multirow{2}{*}{ glucoerucin } & erucin & 4-(methylthio)-butyl-ITC & ER & 1427 & $\mathrm{~B}$ & $161,146,115,85,72,61,55$ & {$[58,59]$} \\
\hline & erucin nitrile & 1-cyano-4-(methylthio) butane & ERN & 1200 & $\mathrm{~B}$ & $129,87,82, \mathbf{6 1}, 55,48,41,47$ & {$[58,59]$} \\
\hline \multirow[t]{2}{*}{ glucoiberin } & iberin & 3-methylsulfinylpropyl-ITC & IB & 1617 & $\mathrm{~B}$ & $163,130,116,102,100,86,72,63,61,41$ & {$[58]$} \\
\hline & iberin nitrile & 4-methylsulfinylbutanenitrile & IBN & 1384 & $\mathrm{~B}$ & $131,78,64,47,41$ & [58] \\
\hline gluconasturtin & benzenepropanenitrile & 2-phenylethyl cyanide & $\mathrm{BPN}$ & 1238 & $\mathrm{~B}$ & $131,91,85,65,63,57,44,51$ & {$[60]$} \\
\hline \multirow[t]{2}{*}{ glucoraphanin } & sulforaphane & 4-methylsulfinylbutyl-ITC & SFP & 1757 & $\mathrm{~A}$ & $160,114,85,72,64,63,61,55.41,39$ & {$[57,59]$} \\
\hline & sulforaphane nitrile & 5-(methylsulfinyl) pentanenitrile & SFN & 1526 & $\mathrm{~B}$ & $145,128,82,64,55,41$ & {$[57,59]$} \\
\hline \multirow[t]{2}{*}{ glucobrassiccin } & indole-3-carbinol & 1H-indole-3-methanol & $\mathrm{I} 3 \mathrm{C}$ & 1801 & B & $144,145,116,108,89$ & {$[61]$} \\
\hline & indoleacetonitrile & 1H-indole-3-acetonitrile & 1IAN & 1796 & B & $\mathbf{1 5 5}, 145,144,130,116,89,101,63$ & [62] \\
\hline pentyl glucosinolate & pentyl-ITC & 1-isothiocyanato-pentane & PITC & 1165 & $\mathrm{~B}$ & $129,114,101,96,72,55,43,41,39$ & [63] \\
\hline glucotropaeolin & benzeneacetonitrile & 2-phenylacetonitrile & BAN & 1137 & A & $\mathbf{1 1 7}, 90,89,77,63,51$ & {$[64]$} \\
\hline
\end{tabular}

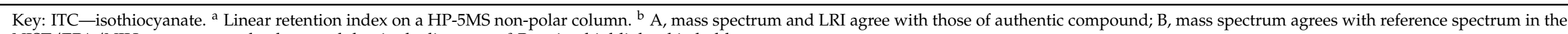
NIST/EPA/NIH mass spectra database and that in the literature. ${ }^{c}$ Base ion highlighted in bold. 


\subsection{Statistical Analysis}

The results are the average of three biological replicates (each replicate consists of leaves from 4-5 cabbage heads) and two technical replicates $(n=6)$. Data obtained were analysed using 2-way ANOVA, with both cabbage accession (or morphotype) and growing condition (glasshouse and field) fitted as treatment effects, and Tukey's HSD multiple pairwise comparison test used to determine significant differences $(p<0.05)$ between samples. Multifactor analysis (MFA) was used to visualise the GSL and GHP data in a minimum number of dimensions (two or three). All statistical analyses were performed in XLSTAT (version 2019.4.2, Addinsoft, Paris, France).

\section{Results and Discussion}

\subsection{Effect of Growing Conditions, Cabbage Morphotype and Accession on Myrosinase Activity}

The myrosinase activity of cabbages grown on the field and in the glasshouse is shown in Figure 1. Myrosinase activity ranged from 12.2 U/g DW (BK-CPNT) to 127.4 U/g DW (SC$\mathrm{PW}$ ) in glasshouse samples and from $31.5 \mathrm{U} / \mathrm{g}$ DW (BK-CPNT and RC-RL) to $154.8 \mathrm{U} / \mathrm{g}$ DW (SC-PW) in field samples. Growing condition (glasshouse versus field), cabbage morphotype, cabbage accession and the interactions between these parameters significantly $(p<0.0001)$ affected myrosinase activity. The myrosinase activity of cabbage accessions within a cabbage morphotype differed significantly for all cabbage morphotypes studied. This agrees with previous reports that myrosinase activity varies within varieties and plant species [65]. Singh et al. [38] and Penas et al. [29] also reported variations in the myrosinase activity of different cabbage varieties within and between cabbage morphotypes. There were significant differences in the myrosinase activity of field and glasshouse grown cabbages across most of the accessions studied. Field grown cabbages had significantly higher myrosinase activity than glasshouse cabbages, except for WC-FEM, where the myrosinase activity of the glasshouse sample was significantly $(p<0.003)$ higher than that of the field grown counterpart.

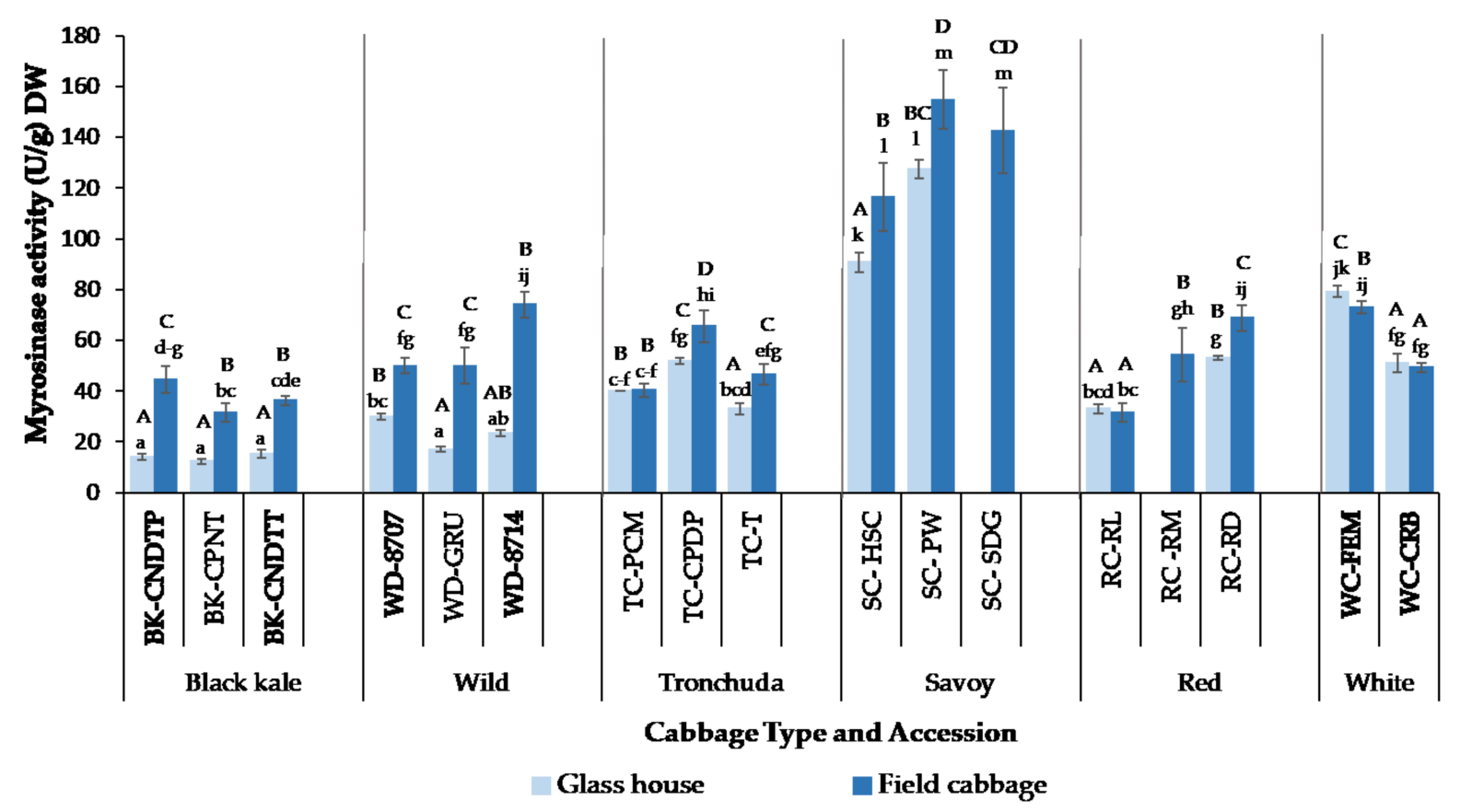

Figure 1. Myrosinase activity of field and glasshouse grown cabbages. Values are means of three biological replicates (each replicate comprising $4-5$ cabbage heads) and two separately extracted technical replicates $(n=6)$. Error bars represent standard deviation from mean values. Missing data points implies cabbage accession did not survive under glasshouse growing conditions. Letters "A-D": bars not sharing a common uppercase letter indicates significant differences $(p<0.0001)$ between accessions and growing conditions within a cabbage morphotype. Letters "a-k": bars not sharing a common lowercase letter indicates significant differences $(p<0.0001)$ between accessions and growing conditions between cabbage morphotypes. See Table 1 for full names of cabbage accessions. 
The myrosinase activity of TC-PCM, RC-RL and WC-CRB accessions did not differ significantly between field and glasshouse grown cabbages. Authors have previously reported that growing/environmental conditions affect myrosinase activity in B. oleracea species [24-26,29], and the results obtained from this study agree with their reports. The lower myrosinase activity of glasshouse cabbages might have been due to higher growth temperatures than those grown in the field. Minimum and maximum glasshouse temperatures were 14 and $43{ }^{\circ} \mathrm{C}$, respectively, while minimum and maximum field temperatures were 6 and $24^{\circ} \mathrm{C}$, respectively (Supplementary Table S1). There are several possible reasons for the differences observed. One hypothesis could be that high temperatures reduced myrosinase enzyme synthesis or led to its more rapid denaturation. Another possible reason may have been that the process of synthesis and degradation of the enzyme (turn-over rate) was occurring faster at the higher growth temperatures, meaning that the plant did not accumulate a pool of enzymes at any one time. However, given that we can only see a snapshot in time when plants are sampled for enzyme assays, and each accession was harvested just once at a consistent time of day, it is not possible to infer the kinetics of these reactions occurring within the plant from the data in the present study. The kinetics of myrosinase synthesis and degradation within the plant is an area that warrants further study. Penas et al. [29], in their study of cabbages grown in different parts of Spain, reported that myrosinase activity was lower in cabbages grown in eastern Spain that were exposed to a higher growing temperature when compared to those grown in northern Spain with lower growing temperatures. It is, however impossible to say unequivocally that the lower myrosinase activity observed in the glasshouse samples is as a result of higher growth temperatures and not due to other stress factors, as we were unable to grow the plants in the glasshouse under lower temperatures similar to those observed in the field due to unavailability of cooling facilities within the glasshouse used in the study.

Another possible reason for the significantly lower enzyme activity in glasshouse cabbages could be due to stress factors during growth. Glasshouse cabbages were grown in pots, which may have led to stress from restricted root volume and reduced the amounts of nutrients (sulphur and nitrogen) available, potentially resulting in fewer enzymes and substrates being synthesized. Cabbage grown in the glasshouse achieved a lower above ground biomass than the field grown ones, indicating some form of stress. This was also evident in the differences in size of the closed heart cabbage heads, with the glasshouse plants having smaller heads than the field plants, as reported in Section 2.1. Their leaves appeared to be thinner and less robust than the field cabbages, as is often found in plants grown in protected environments that are not exposed to stimuli, such as wind, which for decades has been known to encourage the formation of thicker cell walls and smaller cells [66]. Hirai et al. [67] found that under nitrogen and/or sulfur limiting growth conditions, genes encoding myrosinase enzyme synthesis were down-regulated in Arabidopsis in order to facilitate storage of these elements in the form of glucosinolates in the leaf tissue. Yuan et al. [68] and Rodríguez-Hernández et al. [69] showed that salt stress reduced myrosinase activity in radish sprouts and broccoli, respectively. Pests and insect attack in field cabbages may have also led to higher myrosinase synthesis and/or accumulation in the cabbages. Accessions that did not show significantly different myrosinase activities between the two growing environments, or in the case of WC-FEM, higher myrosinase activity in glasshouse samples, might have been able to tolerate the glasshouse conditions and may have found it conducive for growth, while accessions that did not survive in the glasshouse may have found the conditions too harsh. Increased myrosinase activity as a result of abiotic stress, such as salt, temperature and drought, has been reported in various Brassicaceae species [70-72]. Increased myrosinase activity would result in enhanced glucosinolate hydrolysis to beneficial isothiocyanates, which would not only be beneficial to consumers but would also serve as defence compounds for the plants, thereby protecting them against insect and pest attacks. 


\subsection{Protein Content and Specific Myrosinase Activity of Glasshouse and Field Grown Cabbages}

The protein content and specific activity of myrosinase for all accessions and growing conditions studied are presented in Table 4 . The protein content and specific activity of samples studied were significantly $(p<0.05)$ affected by growing conditions and cabbage accession. Protein content did not correlate with myrosinase activity.

Table 4. Protein content ((mg/g \pm SD) DW) and specific activity ((U/mg soluble protein \pm SD) DW) of cabbage accessions grown in the glasshouse and on the field.

\begin{tabular}{|c|c|c|c|c|}
\hline \multirow{2}{*}{$\begin{array}{l}\text { Cabbage Morpho- } \\
\text { type/Accession }\end{array}$} & \multicolumn{2}{|c|}{ Protein Content $(\mathrm{mg} / \mathrm{g} \pm \mathrm{SD}) \mathrm{DW}$} & \multicolumn{2}{|c|}{ Specific activity (U/mg Soluble Protein \pm SD) DW } \\
\hline & Glasshouse & Field & Glasshouse & Field \\
\hline \multicolumn{5}{|l|}{ Black Kale } \\
\hline BK-CNDTP & $29.1 \pm 0.4 \mathrm{gh}, \mathrm{B}$ & $33.7 \pm 0.6^{1, C}$ & $0.5 \pm 0.0^{\mathrm{a}, \mathrm{A}}$ & $1.3 \pm 0.2^{\mathrm{d}-\mathrm{h}, \mathrm{C}}$ \\
\hline BK-CPNT & $24.5 \pm 0.1^{\mathrm{e}, \mathrm{A}}$ & $35.4 \pm 1.0 \mathrm{~m}, \mathrm{D}$ & $0.5 \pm 0.1^{\mathrm{a}, \mathrm{A}}$ & $0.9 \pm 0.1^{\mathrm{a}-\mathrm{d}, \mathrm{B}}$ \\
\hline BK-CNDTT & $25.4 \pm 3.9^{\mathrm{e}, \mathrm{A}}$ & $36.7 \pm 0.7 \mathrm{~m}, \mathrm{E}$ & $0.6 \pm 0.1^{\mathrm{ab}, \mathrm{A}}$ & $1.0 \pm 0.0^{\mathrm{b}-\mathrm{e}, \mathrm{B}}$ \\
\hline \multicolumn{5}{|l|}{ Wild } \\
\hline WD-8707 & $27.4 \pm 0.7^{\mathrm{f}, \mathrm{C}}$ & $31.4 \pm 0.1 .2^{\mathrm{jk}, \mathrm{E}}$ & $1.1 \pm 0.1^{\mathrm{c}-\mathrm{f}, \mathrm{B}}$ & $1.6 \pm 0.1$ ghi, $C$ \\
\hline WD-GRU & $25.3 \pm 0.1^{\mathrm{e}, \mathrm{B}}$ & $29.9 \pm 0.6^{\mathrm{hi}, \mathrm{D}}$ & $0.7 \pm 0.1 \mathrm{abc}, \mathrm{A}$ & $1.7 \pm 0.2^{\text {hij, } C}$ \\
\hline WD-8714 & $18.4 \pm 0.1^{\mathrm{a}, \mathrm{A}}$ & $30.6 \pm 0.8 \mathrm{ij}, \mathrm{DE}$ & $1.3 \pm 0.1^{\mathrm{d}-\mathrm{h}, \mathrm{B}}$ & $2.4 \pm 0.2^{1, D}$ \\
\hline \multicolumn{5}{|l|}{ Tronchuda } \\
\hline TC-PCM & $32.8 \pm 0.1 \mathrm{kl}, \mathrm{D}$ & $33.6 \pm 0.2^{1, \mathrm{E}}$ & $1.2 \pm 0.0^{\mathrm{d}-\mathrm{h}, \mathrm{AB}}$ & $1.2 \pm 0.1^{\mathrm{d}-\mathrm{g}, \mathrm{AB}}$ \\
\hline TC-CPDP & $21.2 \pm 0.2^{b}, \mathrm{~A}$ & $27.8 \pm 0.6^{\mathrm{fg}, \mathrm{B}}$ & $2.4 \pm 0.1^{1, C}$ & $2.4 \pm 0.3^{1, C}$ \\
\hline TC-T & $30.5 \pm 0.2^{\text {hij, } C}$ & $33.1 \pm 0.8^{1, \mathrm{DE}}$ & $1.1 \pm 0.1^{\text {cde, }} \mathrm{A}$ & $1.4 \pm 0.1^{\mathrm{e}-\mathrm{h}, \mathrm{B}}$ \\
\hline \multicolumn{5}{|l|}{ Savoy } \\
\hline SC-HSC & $24.5 \pm 1.0^{\mathrm{e}, \mathrm{A}}$ & $24.6 \pm 1.43^{\mathrm{e}, \mathrm{A}}$ & $3.7 \pm 0.1 \mathrm{~m}, \mathrm{~A}$ & $4.7 \pm 0.3^{\mathrm{n}, \mathrm{B}}$ \\
\hline SC-PW & $24.1 \pm 0.1$ cde, $\mathrm{A}$ & $24.3 \pm 0.3^{\mathrm{de}, \mathrm{A}}$ & $5.3 \pm 0.1^{\circ}, \mathrm{BC}$ & $6.4 \pm 0.5 \mathrm{q}, \mathrm{D}$ \\
\hline SC-SDG & dng & $24.4 \pm 0.5^{\mathrm{de}, \mathrm{A}}$ & dng & $5.8 \pm 0.7 \mathrm{p}, \mathrm{CD}$ \\
\hline \multicolumn{5}{|l|}{ Red } \\
\hline RC-RL & $21.0 \pm 0.5^{b, A}$ & $33.6 \pm 0.6^{1, C}$ & $1.6 \pm 0.1$ ghi, B & $0.9 \pm 0.1^{\mathrm{a}-\mathrm{d}, \mathrm{A}}$ \\
\hline RC-RM & dng & $35.4 \pm 1.0^{\mathrm{m}, \mathrm{D}}$ & dng & $1.5 \pm 0.3^{\mathrm{f}-\mathrm{i}, \mathrm{B}}$ \\
\hline RC-RD & $25.3 \pm 0.1 \mathrm{e}, \mathrm{B}$ & $36.7 \pm 0.7 \mathrm{~m}, \mathrm{E}$ & $2.1 \pm 0.0^{\mathrm{jkl}, \mathrm{C}}$ & $1.9 \pm 0.1 \mathrm{ijk}, \mathrm{C}$ \\
\hline \multicolumn{5}{|l|}{ White } \\
\hline WC-FEM & $21.2 \pm 0.9^{b}, \mathrm{~A}$ & $21.3 \pm 0.4^{\mathrm{b}, \mathrm{A}}$ & $3.8 \pm 0.2 \mathrm{~m}, \mathrm{C}$ & $3.4 \pm 0.2 \mathrm{~m}, \mathrm{~B}$ \\
\hline WC-CRB & $22.8 \pm 0.6^{\mathrm{c}, \mathrm{B}}$ & $23.0 \pm 1.2^{\mathrm{cd}, \mathrm{B}}$ & $2.2 \pm 0.2^{\mathrm{kl}, \mathrm{A}}$ & $2.1 \pm 0.1^{\mathrm{kl}, \mathrm{A}}$ \\
\hline
\end{tabular}

Values are means of three processing replicates and two technical replicates $(n=6 \pm \mathrm{SD})$. SD: standard deviation from mean; dng: did not grow. Letters "A-E": mean values not sharing a common uppercase letter differ significantly $(p<0.05)$ between accessions and growing condition within a cabbage type for each parameter (i.e., protein content and specific activity). Letters "a-q": mean values not sharing a common lowercase letter differ significantly $(p<0.05)$ between cabbage types, accessions, and growing condition for each parameter (i.e., protein content and specific activity). See Table 1 for full names of cabbage accessions.

Savoy and white cabbage accessions, which had the highest myrosinase activity, had the lowest protein contents. Just like myrosinase activity, the protein content of glasshouse samples was significantly lower than the field samples. This might be as a result of plant stress during growth, which prevents the plant from producing more nutrients than required or using up its stored nutrients in order to survive, as previously discussed in Section 3.1. Plant proteins have been reported to react negatively to environmental stress [26]. The results obtained are in agreement with Rosa and Heaney [73], who reported higher protein contents in Portuguese cabbage grown in lower environmental temperatures compared to those grown in higher temperatures.

Specific activity of the cabbages was similar to the myrosinase activity and protein content, with field grown cabbages generally having higher specific activity than the glasshouse cabbages. Savoy and white cabbage accessions had significantly higher specific activities than other cabbage morphotypes, as indeed both were found to have significantly higher total myrosinase activity (Figure 1). White cabbage has previously been reported to have higher specific activity than red cabbage [28], which is in agreement with the results of this study. However, a study conducted by Singh et al. [38] showed red cabbage with a higher specific activity than white and savoy cabbage. This might have been due to the 
differences in varieties studied or protein content of the cabbages, which was not reported in their study.

\subsection{Effect of Cabbage Morphotype and Accession on GSL Profile and Concentration of Field Grown Cabbages}

GSL profiles across cabbage accessions are presented in Figure 1; the statistical output of significant differences within and between cabbage morphotypes is documented in Supplementary Table S2. In total, nine different GSLs were identified across all accessions tested (Table 2): seven aliphatic GSLs, namely sinigrin (SIN), gluconapin (GPN) and epi/progoitrin (PROG), glucoibeverin (GIBVN), glucoerucin (GER), glucoiberin (GIBN) and glucoraphanin (GRPN), and two indole GSLs, glucobrassicin (GBSN) and 4-hydroxyglucobrassicin (4-HOH). PROG, GIBN and GRPN were the most abundant GSLs across all accessions studied, with 4-HOH, GIBVN and GER being the least abundant. 4-HOH was present in negligible amounts $(<1.0 \mu \mathrm{mol} / \mathrm{g}$ DW $)$ in all accessions, contributing not more than $1 \%$ to the total GSL content of the cabbages. When considering the ratio of total aliphatic to indole GSL concentrations in the accessions, over $60 \%$ of total GSL concentration was made up of aliphatic GSLs, with less than 30\% from indole GSLs, with the exception of savoy SC-PW accession, where indole GSL comprised 36\% of total GSL concentration (Supplementary Table S2).

GSL profiles and concentrations varied across cabbage accessions and differed significantly $(p<0.05)$ in some cases between and within cabbage morphotypes and accessions. Only five of the nine individual GSLs identified in the cabbages studied were found in black kale accessions:-GIBN, GRPN, GBSN, 4-HOH and GER-the last of which was present in BK-CNDTT alone. GRPN was the major GSL present in black kale accessions, consisting of over $50 \%$ on average of the total GSL content of black kale. The proportion of GRPN is similar to those previously reported by Kushad et al. [74] but much higher than those reported by Cartea et al. [40]. Previous studies detected SIN and PROG in kale and reported SIN as the main GSL in kale varieties [32,40,74]; however, SIN and PROG were not detected in the current study. There was a significant difference in total and individual GSL concentrations within black kale accessions, except for 4-HOH, which did not differ significantly $(p=0.401)$. BK-CPNT had the highest total GSL content $(47.5 \mu \mathrm{mol} / \mathrm{g} \mathrm{DW})$.

GIBVN and GER were not identified in any of the wild and tronchuda cabbage accessions studied, while GIBN and GRPN were identified in all accessions except for WD-8707 accession. The concentration of individual GSLs differed significantly $(p<0.0001)$ across all wild and tronchuda cabbages. PROG and GPN were the most abundant GSLs in WD-8707 and WD-8714, while PROG and GRPN were the most abundant in WD-GRU. In tronchuda cabbages, SIN, GIBN and GBSN were at the highest concentrations, with SIN comprising up to $42 \%$ in TC-T.

A previous study [40] on GSL profile and concentrations in tronchuda cabbage identified 14 GSLs, compared to seven found in this study. However, GER was not identified in both studies, and proportions of the individual GSLs identified in both studies were similar.

The total GSL content of wild and tronchuda accessions differed significantly $(p<0.01$ and $p<0.0001$, respectively) between accessions within each cabbage morphotype. The most abundant GSLs in savoy cabbages were GIBN, SIN and GBSN, with GIBN concentrations as high as $61.3 \mu \mathrm{mol} / \mathrm{g}$ DW (57\% of the total GSLs) in SC-SDG. GER was not identified in savoy accessions, and GPN was present in very low amounts in SC-SDG only. Similar proportions of savoy GSLs were reported by Ciska et al. [41] and Hanschen and Schreiner [43], but in both studies more individual GSLs were identified in the savoy varieties investigated than those reported in this study. For example, both studies identified GER in savoy cabbages, although present in trace amounts in the Ciska et al. [41] study. The total GSL content of savoy cabbages ranged from $47.6 \mu \mathrm{mol} / \mathrm{g}$ DW to $108.5 \mu \mathrm{mol} / \mathrm{g}$ DW. SC-SDG accession had significantly higher $(p<0.0001)$ total GSLs than SC-HSC and SC-PW, with SC-HSC having significantly lower total GSLs than the other two accessions.

In red and white cabbages, PROG, GIBN and GRPN were the most abundant GSLs. GBSN was also abundant in WC-CRB and RC-RL accessions, while GER was not identified 
in either accession. The concentrations of GRPN, GIBVN and GER did not differ significantly between red cabbage accessions. WC-CRB had significantly higher amounts of SIN, GIBN, GBSN and total GSL compared to WC-FEM, but differences in PROG and GRPN content were not significant. The total GSL content of RC-RL was significantly $(p<0.0001)$ higher than the other two red cabbage accessions. The results obtained agree with those previously reported [22,41,43]. However, a few studies disagree with the findings of this study; a previous study conducted by Park et al. [75] quantifying red cabbage GSL reported SIN absent in red cabbage, while Zabaras et al. [76] found GPN as the most abundant GSL in red cabbage.

Individual GSLs and total average GSL concentrations differed significantly $(p<0.0001)$ across all accessions, irrespective of cabbage morphotype. Total average GSL concentrations of accessions studied ranged from $18.9 \mu \mathrm{mol} / \mathrm{g}$ DW (BK-CNDTT) to $163.1 \mu \mathrm{mol} / \mathrm{g}$ DW (WD-8714). These differences were due to variations in GSL profiles and concentrations of individual GSLs. Wild cabbages generally had higher total GSL concentrations (Figure 2b) than other cabbage morphotypes, and these high concentrations were driven by significantly higher amounts of PROG in wild cabbages. Lower concentrations of total GSL observed in black kale accessions ( $18.9 \mu \mathrm{mol} / \mathrm{g}$ DW to $47.5 \mu \mathrm{mol} / \mathrm{g}$ DW) were due to lower numbers and concentrations of individual GSLs compared to the other cabbage morphotypes studied (Figure 2a). The variability in GSL concentrations between and within cabbage morphotypes and accessions is in agreement with previous reports that GSL profiles and concentrations vary between Brassica species and varieties [5,29,39,40,43,52,77]. The difference in GSL profiles of Brassica vegetables has been linked to genetic factors, while interactions between environmental and genetic factors are largely responsible for differences in GSL concentrations [8]. In general, concentrations of individual and total GSL of the gene bank cabbages reported in this study are much higher than those reported for commercial and gene bank cabbage varieties/accessions in the literature $[29,40,41,43,74]$. One reason for this may be due to the different varieties/accessions studied, implying that gene banks may indeed be a useful source from which to select accessions with higher GSL concentrations.

Differences in postharvest handling/time could have also contributed to the higher abundance of GSLs observed in the current study. Most varieties used in the literature were obtained from the supermarket and would have gone through a standard commercial supply chain upon harvest, unlike the samples used in this study, which were transferred to the laboratory immediately after harvest. The absence of commercial postharvest storage and handling processes in the current study could account for the differences observed between the samples and those reported in the literature. Total GSL abundance has been shown to decrease in Brassica vegetables stored for 7 days at $4-8{ }^{\circ} \mathrm{C}$ [78]. Lastly, differences in the conditions under which the plants were grown and/or harvested could also be responsible for the variations in GSL concentrations observed. This suggests that it is not only important that the right accession/variety is selected, but it must also be grown under optimal conditions and given as short a supply chain as possible to achieve optimum GSL abundance in the plants. The higher GSL concentrations in the present study can enhance the potential health benefits that may be derived from their consumption.

The differences in GSL profiles and concentrations of the accessions studied can potentially influence the sensory and health properties of the cabbages. For example, the absence of SIN and PROG in black kale accessions and higher concentrations of PROG reported in wild cabbage accessions may potentially influence the sensory characteristics of these cabbages, given SIN and PROG have been linked with bitter taste in Brassica vegetables [22,79]. On the other hand, higher amounts of GRPN (the precursor GSL for SFP formation linked to several health promoting properties of Brassicas) in kale, red and white cabbages could enhance the potential health benefits derived from their consumption [80]. The differences in cabbage accessions, growing conditions and geographical location, as well as environmental factors during cabbage cultivation, all play a vital role in GSL profile and concentration and therefore make comparing results between different studies difficult. 


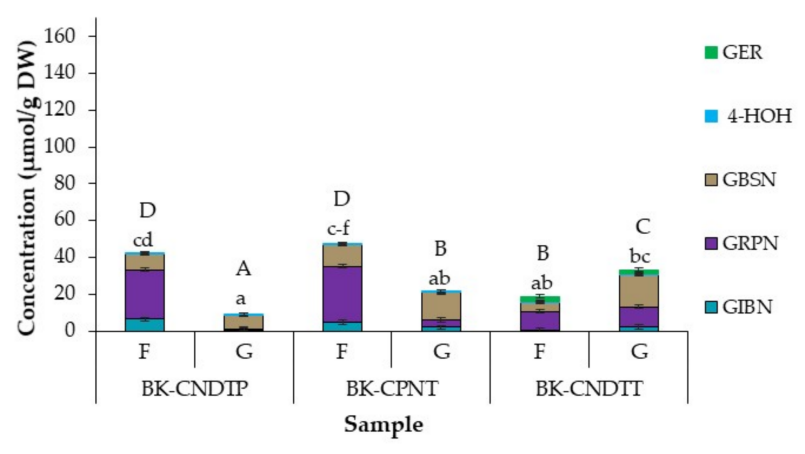

(a) Black kale

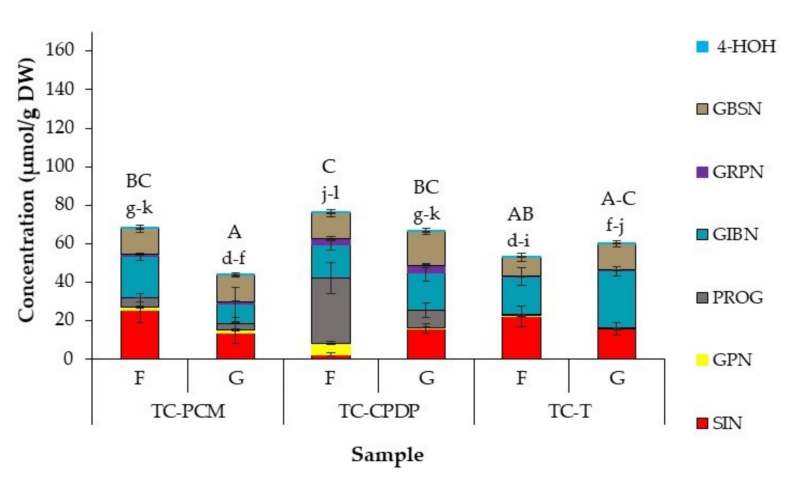

(c) Tronchuda cabbage

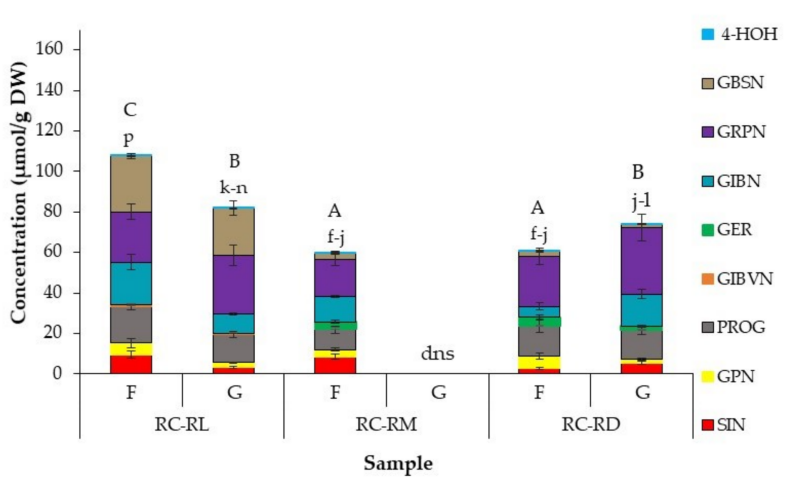

(e) Red cabbage

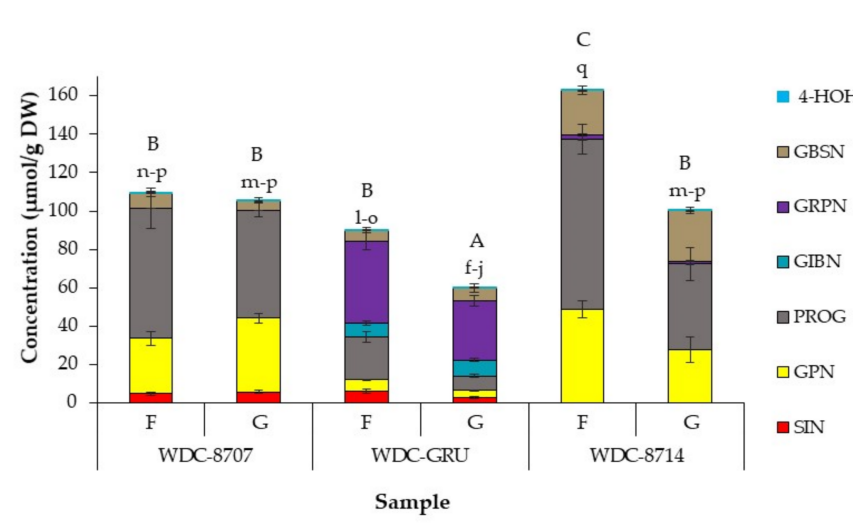

(b) Wild cabbage

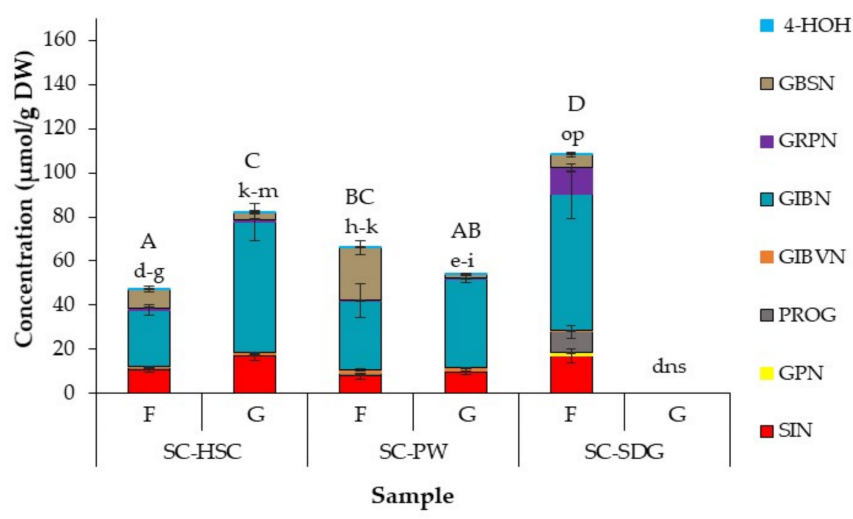

(d) Savoy cabbage

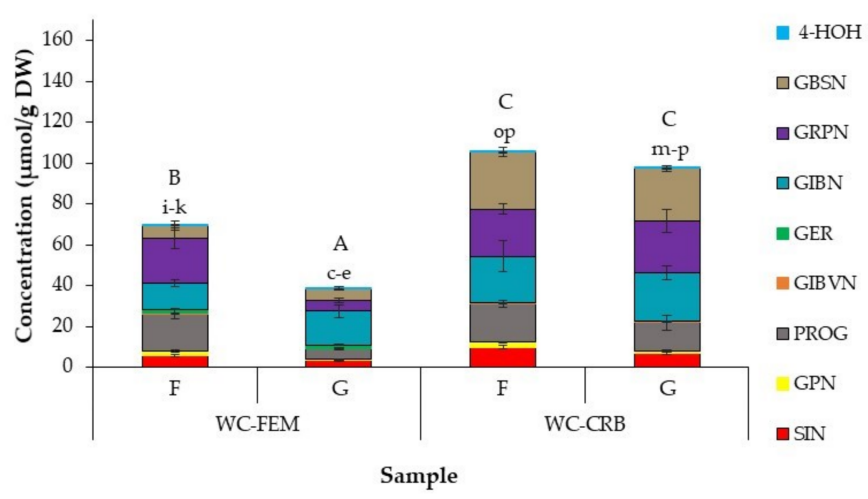

(f) White cabbage

Figure 2. Glucosinolate concentrations ( $\mu \mathrm{mol} / \mathrm{g}$ DW) in different accessions of (a) Black kale; (b) Wild cabbage; (c) Tronchuda cabbage; (d) Savoy cabbage; (e) Red cabbage; and (f) White cabbage grown in the field and glasshouse. Error bars represent standard deviation from mean values. Letters above bars refer to differences in total GSL concentration. Letters "A-D": bars not sharing a common uppercase letter differ significantly $(p<0.05)$ between accession and growing conditions within a cabbage morphotype (i.e., within each separate graph). Letters "a-q": bars not sharing a common lowercase letter differ significantly $(p<0.0001)$ between cabbage morphotypes, accessions, and growing conditions (i.e., between the separate cabbage morphotype graphs). Abbreviations: $\mathrm{F}=$ Field, $\mathrm{G}=$ glasshouse; dns = did not survive. For abbreviations of accessions and compounds see Table 1 (cabbage accessions) and Table 2 (GSLs). 


\subsection{Effect of Growing Conditions on GSL Concentrations in Cabbage Accessions}

The effect of growing conditions on GSL concentration is presented in Figure 1, with significant differences within and between cabbage morphotypes presented in Supplementary Table S2. While the GSL profile of cabbage accessions studied did not differ between growing conditions, there was a difference in GSL abundance between glasshouse and field grown cabbages. Total GSL concentrations in field grown samples ranged from $18.9 \mu \mathrm{mol} / \mathrm{g}$ DW (BK-CNDTT) to $163.1 \mu \mathrm{mol} / \mathrm{g}$ DW (WD-8714) and glasshouse samples from $8.81 \mu \mathrm{mol} / \mathrm{g}$ DW (BK-CNDTP) to $105.5 \mu \mathrm{mol} / \mathrm{g}$ DW (WD-8707). WD-8714 had significantly $(p<0.0001)$ higher concentrations of total GSLs compared to all other accessions, and this was largely due to the abundance of PROG and GPN, making up $83 \%$ and $69 \%$ of total GSLs in field and glasshouse samples, respectively.

Cabbages grown in the field had higher total GSL concentrations than glasshouse samples across most accessions studied, with a few exceptions (BK-CNDTT, TC-T, SC-HSC, and RC-RD), where total GSL concentrations were higher in glasshouse samples. These differences were significant in some but not all cases. Growing conditions significantly affected individual GSL concentrations between and within cabbage morphotypes and accessions. With the exception of black kale accessions, both field and glasshouse cabbages were predominantly abundant in aliphatic GSLs, with averages of 82 and $78 \%$, respectively across all accessions, while indole GSLs comprised only 18 and $22 \%$ of total GSLs in field and glasshouse samples, respectively. In black kale accessions, however, growing conditions seemed to influence the ratio of aliphatic to indole GSL present in the samples. All black kale accessions grown in the glasshouse had much higher total indole GSL, with up to seven-fold differences reported in BK-CNDTP samples (Supplementary Table S2). The differences observed are mainly due to differences in the ratio of individual aliphatic to indole GSL present in the samples and not higher concentrations of indole GSLs in the glasshouse samples, as there was no significant difference observed in the concentrations of the most abundant indole GSL, GBSN, present in the samples between growing conditions (except for BK-CNDTT).

There was no clear pattern for the abundance of individual GSLs, as some GSLs were significantly higher in glasshouse samples for some accessions, but lower or not significantly different in others. PROG and GRPN were either significantly higher in field samples or did not significantly differ from glasshouse samples within accessions, except for RC-RD accession, where GRPN was significantly higher $(p<1.0001)$ when grown in the glasshouse. GRPN abundance in BK-CNDTP and BK-CPNT field grown accessions was up to $90 \%$ more than the corresponding glasshouse grown cabbages. GBSN was the most stable GSL across growing conditions, as there was no significant difference $(p=0.101)$ in GBSN between field and glasshouse cabbages.

Growing conditions such as growth temperature and photoperiod have been shown to influence the abundance of GSLs. There are several possible reasons for the differences observed in GSL concentrations in the different growing conditions. The higher total GSL content reported in most field samples could be due to production of higher amounts of GSLs by the plant in response to insect and pest attack on the field when compared to glasshouse samples. GSL compounds are plant metabolites produced by plants for defence against stress and attack from insect and pests [8,81]. In addition, the higher amount of GSLs in field samples could also be due to the lower average temperatures during growth $\left(6\right.$ to $\left.24{ }^{\circ} \mathrm{C}\right)$ compared to the higher temperatures in the glasshouse $\left(14\right.$ and $\left.43^{\circ} \mathrm{C}\right)$ (Supplementary Table S1). Growth temperatures have been reported to influence GSL concentrations in Brassica vegetables. Brassica vegetables are generally thought to be cool weather crops, with average growing temperatures between $4-30{ }^{\circ} \mathrm{C}$ [82]. The optimum temperature for growth varies between different types of Brassicas and going below or above that temperature could affect GSL concentrations. The exact mechanism of GSL biosynthesis under different temperature conditions is unclear because of several interacting factors, such as drought and photoperiod, but it has been reported that plant stress due to high or low growing temperatures may enhance activities of transcription factors 
such as MYC2 and MYB28, which promote GSL biosynthesis [42,83]. Literature studies have, however, generally reported higher GSLs at higher growing temperatures; Rosa and Rodrigues [27] reported a higher GSL content in young cabbage plants when grown at $30{ }^{\circ} \mathrm{C}$ compared to $20^{\circ} \mathrm{C}$. Lower GSL concentrations was reported in kale grown at lower temperatures compared to those grown at higher temperatures [32,33]. In addition, several authors have reported higher GSL concentrations in spring/summer grown cabbages (average temperatures between $25-30{ }^{\circ} \mathrm{C}$ ) compared to autumn grown plants (temperatures $<20^{\circ} \mathrm{C}$ ) [29,39-41]. The lower amounts of GSL accumulated in glasshouse plants could also be the result of plant growing conditions. Glasshouse samples were grown in pots with drainage holes to allow excess water to seep out. However, this could have also led to sulphur leaching, leading to sulphur deficiency in the soil, and plants were not fed with sulphur fertilizers. Sulphur is a major precursor for GSL biosynthesis, and its deficiency has been reported to reduce GSL concentrations in Brassica plants, especially aliphatic GSLs, as sulphur deficiency limits methionine synthesis (basic substrate for aliphatic GSL biosynthesis) as opposed to tryptophan, a non-sulphur amino acid and precursor for indole GSL biosynthesis [84]. On average, reduced amounts of aliphatic GSLs were accumulated in glasshouse plants compared to field plants, while glasshouse samples accumulated higher amounts of indole GSLs than field samples. Sulphur was reported to influence the aliphatic GSL concentrations in rapeseed more than indole GSL [84]. However, glasshouse plants, which had significantly higher GSL concentrations compared to their field counterparts, may have found the glasshouse conditions more favourable than other accessions, which resulted in enhanced GSL production.

The results of this study show that cabbages differ in their requirements for growth, and it is important to plant cabbage accessions in growing conditions that are best suited for their maximum development, as individual plants respond differently under different environmental conditions. Optimizing agronomy practices and applying limited abiotic stress in a controlled manner could be a way of increasing myrosinase activity and GSL production in some Brassica species.

\subsection{Effect of of Cabbage Morphotype and Accession on Glucosinolate Hydrolysis Products (GHPs)} of Field Grown Cabbages

A total of 22 GHPs were identified and quantified from the cabbage accessions studied, comprising 11 ITCs and 11 nitriles/epithionitriles (Table 3). Concentrations of GHPs are presented in Figure 2, with significant differences between and within cabbage morphotypes and accessions presented in Supplementary Table S3. Results are expressed as sulforaphane equivalents.

The type and concentration of GHPs formed differed between cabbage accessions. Predominant GHPs did not differentiate between accessions within a cabbage morphotype but varied across cabbage morphotypes. There was a significant difference in the concentrations of individual and total GHPs formed within and between cabbage morphotypes and accessions (Figure 3 and Supplementary Table S3). Wild cabbage accessions had the highest levels of GHPs formed $(8.79 \mu \mathrm{mol} / \mathrm{g}$ DW-8.6 $\mu \mathrm{mol} / \mathrm{g}$ DW; Figure $2 \mathrm{~b})$ and tronchuda accessions the lowest $(0.95 \mu \mathrm{mol} / \mathrm{g}$ DW-3.27 $\mu \mathrm{mol} / \mathrm{g}$ DW; Figure 2c).

GHPs of GRPN and GBRN were the main GHPs detected in black kale accessions, with nitrile concentrations accounting for $74-89 \%$ of the total GHPs. BK-CPNT accessions had significantly lower total GHPs than BK-CNDTP. Isomers of CHETB, nitriles of PROG hydrolysis, were the most abundant GHPs formed in wild cabbages, except for WD-GRU, which had higher amounts of GN (PROG ITC) compared to the nitriles formed. This was unexpected, and it is unclear why this happened, because more nitriles than ITCs were formed for other GSLs present in the same sample. A possible explanation for this could be the activity of epithiospecifier modifier proteins (ESMs), enhancing the activity of specific myrosinase isoenzymes, which hydrolyse PROG present in the samples. ESM inhibits the activity of ESP, preventing the formation of nitriles and epithionitriles, and instead promotes ITC formation $[15,85,86]$. GN have been associated with bitter taste [87] and adverse effects on thyroid metabolism, leading to goitre formation. The reports on goitre 
formation are limited and based on animal studies, which show that average daily intake is not enough to produce adverse effects in humans [8]. However, to limit the health risks, genetic manipulation and selective breeding methods used to increase GRPN contents by threefold in 'Beneforte' broccoli [88] could be employed to reduce PROG contents in the wild accessions. The main GHPs of tronchuda accessions were CETP and IBN, nitriles of SIN and GIBN, respectively. Total GHPs of TC-CPDP were significantly higher than TC-T. IBN and IB (GIBN hydrolysis products) were the most abundant GHPs in savoy cabbages, and SFP and SFN (hydrolysis products of GRPN) the most abundant in red and white cabbages.

In savoy, SC-HSC varied significantly from SC-PW and SC-SDG accessions, containing up to $60 \%$ more GHPs than the other two accessions. The much lower concentrations of GHPs in SC-PW compared to SC-HSC were unexpected due to similar concentrations of GSLs in both accessions. A similar trend was noticed between WC-CRB and WC-FEM accessions, where much lower GHPs were formed in WC-CRB accession, with significantly higher GSLs than WC-FEM. This might be related to variation in myrosinase and ESP activities within the samples. As previously discussed in Section 3.1, WC-FEM had significantly higher myrosinase activity than WC-CRB (Figure 1), which may explain the higher concentrations of GHPs formed. However, this is not the case in savoy cabbages, as SC-PW had the highest myrosinase activity (see Figure 1). It is hypothesized that myrosinase isoenzymes and ESP of SC-PW accession may be less stable than the other accessions and was, therefore, denatured before permitting full hydrolysis. As previously discussed, ESM activities promoting ITC formation may also be responsible for the higher GHP concentrations observed. For example, although GIBN concentration in WC-FEM was significantly $(p<0.0001)$ lower than that of WC-CRB, the amount of IB, the ITC formed from GIBN, was significantly $(p<0.0001)$ higher in WC-FEM than in WC-CRB. Another possible reason for the variation in GHP concentrations could be due to the type of myrosinase isoenzyme present within the samples. It has been reported that myrosinase isoenzymes differ in the rate at which they hydrolyse individual GSLs, though little is known of their substrate specificity. James and Rossiter [89] found that in the presence of ascorbic acid, two myrosinase isoenzymes identified in Brassica napus L. differed in the way they degraded SIN and neoglucobrassicin (NEO), with SIN being degraded more rapidly than NEO by both isoenzymes under the same conditions. While there are limited studies on the conversion ratio of GSLs to GHPs, studies on GHP formation in Brassica oleracea [43] and rocket salad [42] have shown that conversion of GSLs to GHPs is not always a linear reaction and GHP concentrations are generally much lower than the precursor GSL concentrations.

Several GHPs were identified in cabbage accessions where their GSLs were not detected: tiny amounts of 3BITC (GPN hydrolysis product) were formed in BK-CNDTT; 4MBN (nitrile of GIBVN) in tronchuda; EVN (GPN nitrile) in savoy cabbages; and ER and ERN (GER GHPs) in red and white cabbages. PEITC and BPN (GHPs of gluconasturtiin), PITC and BAN were also formed in most accessions. This could be due to concentration of the respective GSLs being below the limits of detection of the LC-MS ${ }^{2}$ instrument used. A previous study of turnips detected GHPs of glucoberteroin, though the intact GSL was not detected [90]. A recent study on horseradish, wasabi, watercress, and rocket also detected GHPs, where their intact glucosinolates were not identified [91]. The profile of GHPs in this study is in agreement with the study of Hanschen and Schreiner [43]. However, in their study, they found CETP (nitrile from SIN hydrolysis) as the main GHP in savoy, red and white cabbages, which is inconsistent with this study, where GIBN GHPs (IB and IBN) and GRPN GHPs (SFP and SFN) were the main compounds detected. This difference can be attributed to the different varieties/accessions studied.

In general, the relationship between individual GSLs and their corresponding GHPs within an accession was as expected, where the dominant GSL resulted in their corresponding dominant GHPs, which is helpful in confirming the efficiency and accuracy of the GHP extraction method. Overall, nitriles and epithionitriles were the major hydrolysis products formed across all cabbage accessions, as has been reported previously in raw 
cabbage [62,92]. This is due to the activity of ESP and other nitrile forming proteins present in the samples, which hydrolyse GSLs to epithionitriles and nitriles instead of the more beneficial ITCs [92].

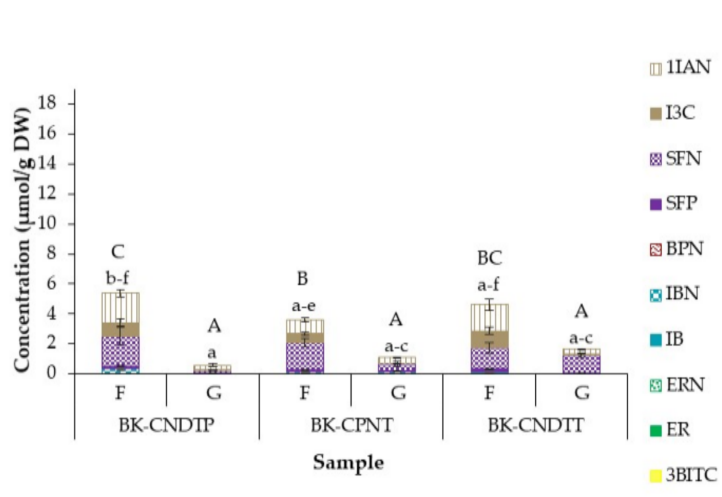

(a) Black kale

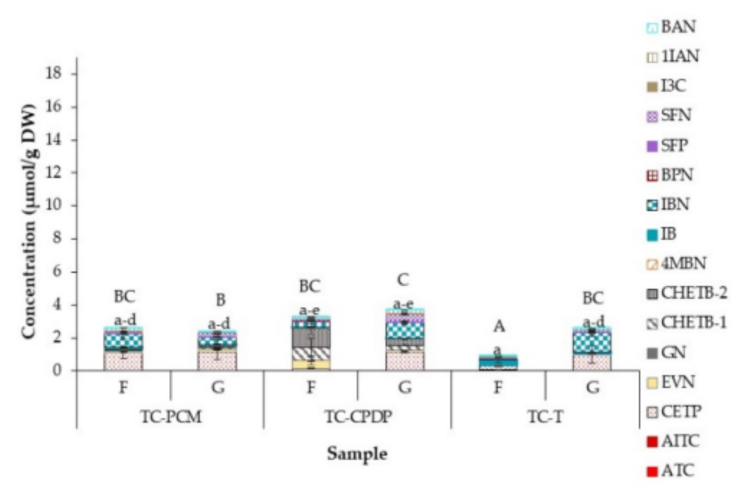

(c) Tronchuda cabbage

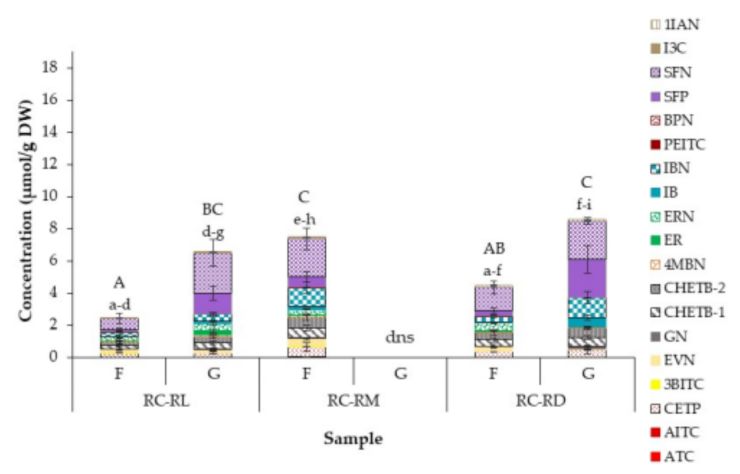

(e) Red cabbage

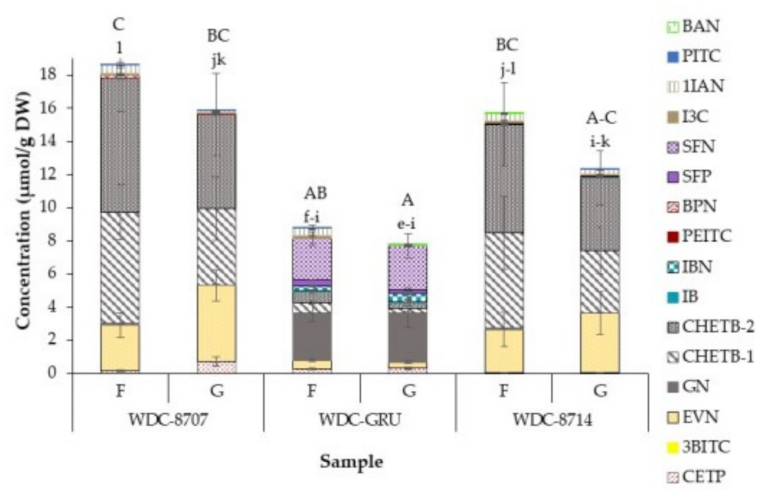

(b) Wild cabbage

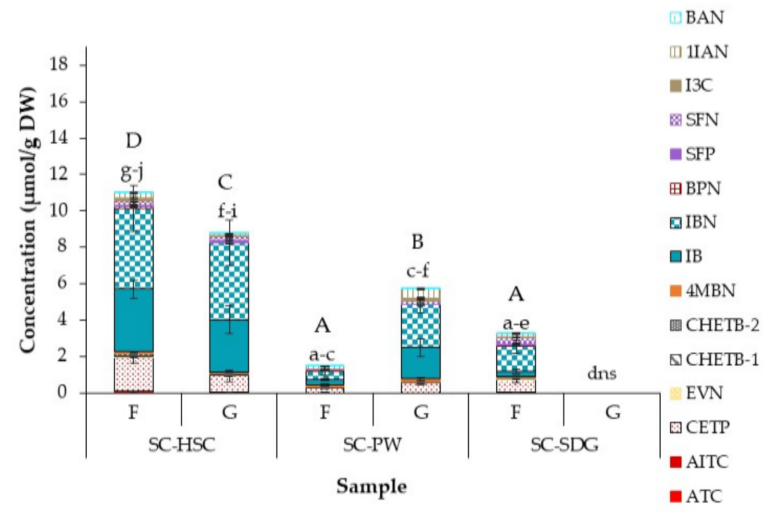

(d) Savoy cabbage

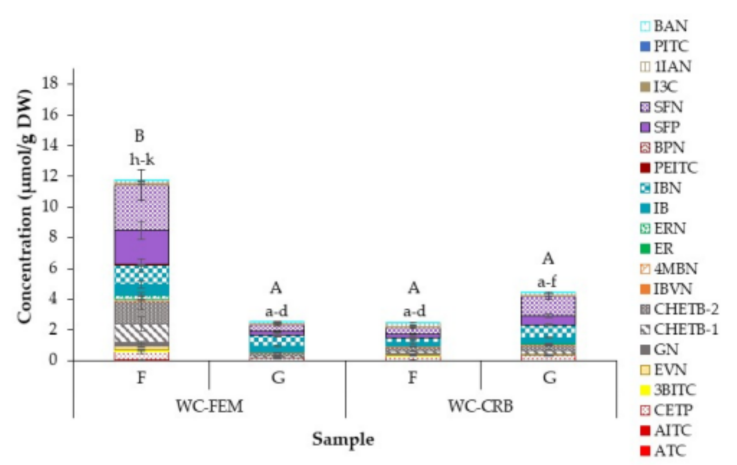

(f) White cabbage

Figure 3. Glucosinolate hydrolysis products (GHPs) ( $\mu \mathrm{mol} / \mathrm{g}$ DW) in different accessions of (a) Black kale; (b) Wild cabbage; (c) Tronchuda cabbage; (d) Savoy cabbage; (e) Red cabbage; and (f) White cabbage grown in the field and glasshouse. Error bars represent standard deviation from mean values. Letters above bars refer to differences in total GHP concentration. Letters "A-D": bars not sharing a common uppercase letter differ significantly $(p<0.05)$ between accessions and growing conditions within a cabbage morphotype (i.e., within each separate graph). Letters "a-1": bars not sharing a common lowercase letter differ significantly $(p<0.0001)$ between cabbage morphotypes, accessions, and growing conditions (i.e., between the separate graphs). Compounds with colour shades similar to one another are GHPs of corresponding GSLs presented in Figure 2. Abbreviations: $F=$ Field; $G$ = glasshouse; dns = did not survive. For abbreviations of accessions and compounds see Table 1 (cabbage accessions) and Table 3 (GHPs). 


\subsection{Effect of Growing Condition on GHP Concentrations}

GHP profile and concentration in the two different growing conditions studied is presented in Figure 3, with the significant differences between growing conditions reported in Supplementary Table S3. The profile of the GHPs detected were similar between growing conditions, with a few exceptions. For example, BPN was identified in black kale field samples but not detected in glasshouse samples. GHP concentrations in field and glasshouse ranged from $0.95 \mu \mathrm{mol} / \mathrm{g}$ DW (TC-T) to $18.6 \mu \mathrm{mol} / \mathrm{g}$ DW (WD-8707) and $0.59 \mu \mathrm{mol} / \mathrm{g}$ DW (BK-CNDTP) to $15.9 \mu \mathrm{mol} / \mathrm{g}$ DW (WD-8707), respectively. Within accessions, total GHP accumulation was significantly higher in field plants than glasshouse, except for wild cabbage accessions, TC-PCM and WC-CRB, where total GHPs were higher in glasshouse samples; however, the differences were not significant, except in WC-CRB, where a significant difference was observed. Generally, total GHP concentrations followed a similar pattern to total GSLs, with a few exceptions. For example, the BK-CNDTT glasshouse sample had significantly lower total GHPs compared to the field sample (Figure 3a), despite the significantly higher total GSL in the glasshouse sample (Figure 2a). Significantly higher myrosinase activity, and possibly ESP activity, in the BK-CNDTT field compared to glasshouse sample may have led to the formation of more GHPs (Figure 1). A similar trend was observed in savoy accessions, where an abundance of GSL under one growing condition did not necessarily result in higher amounts of GHP formed. The results obtained in our study are in agreement with those reported by Jasper et al. [42], where growth temperatures had different effects on the amount of GSL and GHPs formed in rocket salads.

In summary, the results of this study show the importance of having both high myrosinase activity and GSL accumulation in plants, as they have a direct impact on the amount of hydrolysis compounds formed. It is therefore important to ensure that cabbages are cultivated under optimised growing conditions (such as temperature, available sulphur/nitrogen and controlled biotic stress) that favour both high myrosinase and GSL accumulation and not only one or the other.

\subsection{Multifactor Analysis (MFA) of GSLs and GHPs Identified in Cabbage Accessions Grown under Two Different Conditions}

To investigate the underlying structure of the results, MFA was performed on the GSL and GHP data from the cabbage accessions. Figure 4 shows distribution of the cabbage accessions as well as the scores and loadings of MFA performed on the mean data of GSLs and GHPs. Dimensions 1 and 2 (F1, F2) explained $42 \%$ of the variance in the data, but other dimensions did not provide any new information; therefore, only F1 and F2 are presented and discussed. The plot demonstrates that individual GSLs were positively correlated with their corresponding GHPs. From the plot, it is clear that cabbages were mostly distinguished based on morphotype rather than accessions or growing conditions, except for wild cabbage accessions, where there was a clear separation of WD2 (WD-GRU) from WD1 (WD-8707) and WD3 (WD-8714).

Based on the MFA, samples were grouped into three distinct clusters: one cluster comprised of black kale, red cabbage, white cabbage and WD-GRU accessions, another tronchuda and savoy cabbage accessions, and the final cluster WD-8707 and WD-8714 accessions. Black kale, red cabbage, white cabbage and WD-GRU correlated positively with GRPN, GER, 4-HOH and their hydrolysis products. Tronchuda and savoy cabbage samples correlated positively with GIBN, GIBVN, SIN and their hydrolysis products. WD1 and WD2 correlated positively with GPN and PROG and their nitriles, as well as total GSLs and GHPs, but was negatively correlated with black kale, red cabbage, white cabbage and WD-GRU accessions. An additional Pearson correlation demonstrating significant correlations $(p<0.05)$ between various GSLs and GHPs is presented in Supplementary Table S4. GIBN correlated negatively $\left(\mathrm{r}^{2}>-0.3 ; p<0.01\right)$ with PROG and its hydrolysis products, GPN and its hydrolysis products, and PITC. On the contrary, GPN was strongly positively correlated $\left(\mathrm{r}^{2}>0.6 ; p<0.0001\right)$ with PROG and its hydrolysis products, EVN, PITC, total GSL and total GHPS. Total GSLs were significantly positively correlated $\left(\mathrm{r}^{2}=0.5\right.$; 
$p<0.01)$ with total GHPs. Strong significant positive correlations $\left(\mathrm{r}^{2}>0.5 ; p<0.05\right)$ were observed between individual GSLs and their corresponding GHPs. For example, GRPN was positively correlated with SFP and SFN $\left(\mathrm{r}^{2}>0.5\right.$ and $0.8 ; p<0.01$ and $p<0.0001$ respectively).

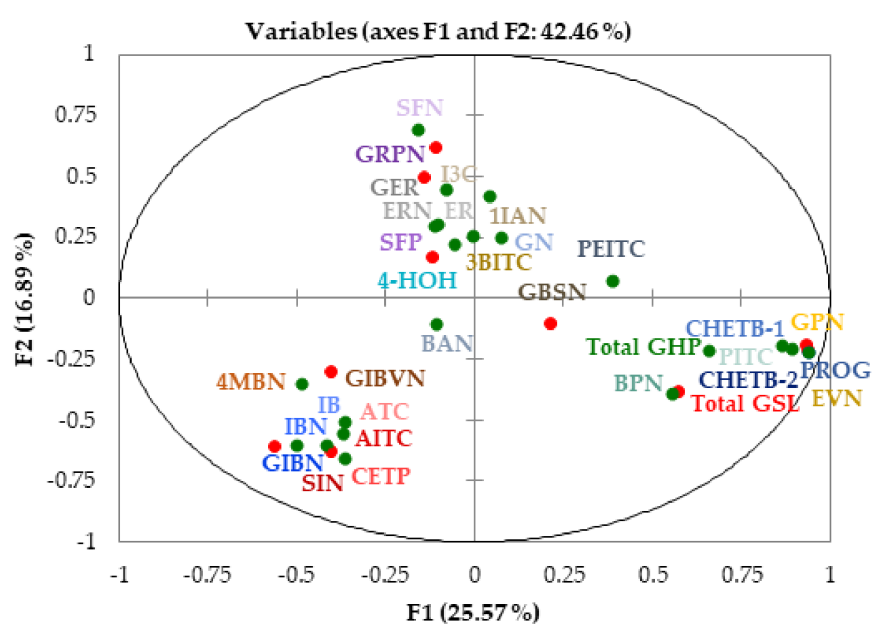

(a)

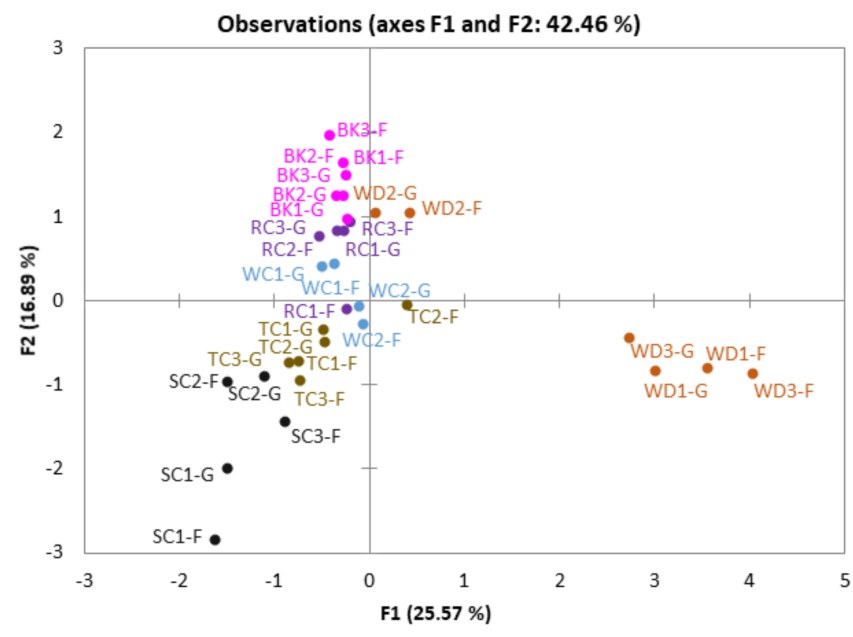

(b)

Figure 4. MFA map of glucosinolates and glucosinolate hydrolysis products (a) distribution of variables and (b) sample distribution. For codes and distribution on plot, refer to Table 1 (cabbage accessions) and Tables 2 and 3 (compounds). Compounds with different shades of the same colour in Figure 3a refer to the GSL and corresponding GHP. Key: F = Field ; $\mathrm{G}=$ Glasshouse $; \bullet \mathrm{GSL}=$ Glucosinolates; $\bullet \mathrm{GHPs}=$ Glucosinolate hydrolysis products; $\bullet$ BK= Black kale; $\bullet \mathrm{WD}=\mathrm{Wild}$ cabbage; $\bullet$ TC = Tronchuda cabbage; $\bullet$ SC = Savoy cabbage; $\bullet$ RC = Red cabbage; $\bullet$ WC $=$ White cabbage.

It is obvious that the separations observed between samples are mainly driven by differences in GSLs and GHPs most accumulated in the samples: GN, GRPN, GER, 4-HOH and their GHPs in black kale, red cabbage, white cabbage and WD-GRU accessions; GIBN, SIN, GIBVN and their GHPs in tronchuda and savoy cabbage accessions; and lastly, PROG, GPN and their GHPs in WD-8707 and WD-8714 accessions. WD-8707 and WD-8714 had the highest concentration of total GSLs and GHPs, and this was responsible for the positive correlation of these accessions to total GSLs and GHPs observed. It is worth mentioning that PROG and CHETB, which were largely responsible for the high concentrations of total GSLs and GHPs in these accessions, correlated positively with total GSLs and GHPs. The result obtained provides a clear picture of the similarities and differences in GSL and GHP profile and concentrations of the different cabbage morphotypes and accessions studied.

Like any other study, some limitations were encountered in this study. First, the cabbage seeds used in the study were obtained from a gene bank. This means they have not been bred for uniformity in terms of plant characteristics and abundance of phytochemical compounds. Breeding programmes to date have mostly focused on developing disease-resistant and environmentally resilient crops, with less emphasis on the content of phytochemical compounds. This implies that there may be large variations in phytochemical compounds between cabbage heads/plants of the same accession, as has been observed in Marathon broccoli heads [93], and this may have influenced the results obtained in the present study. To reduce the effects of possible variation between plant heads, four to five heads were mixed together to obtain a representative sample. However, considering the amounts of heads used during the study, some variations may still have existed within the samples.

Second, the GC-MS method used for GHP analysis was long and required several steps to ensure that all GHPs present in the sample could be identified. However, some GHPs may have been lost or converted into other compounds in the process due to their very volatile and unstable nature. Though care was taken during the analysis to 
prevent losses, the rigorous analytical method may have led to some losses of the more volatile compounds.

\section{Conclusions}

In line with the primary hypothesis of the study, the results demonstrated that myrosinase activity as well as profiles and concentrations of GSLs and GHPs were all influenced by growing conditions, cabbage morphotypes and accession. However, in agreement with our secondary hypothesis, the profile and concentration of GSLs and GHPs formed were substantially more influenced by cabbage morphotype than accession. The study showed that planting cabbages in high growth temperatures and stressful conditions resulted in lower myrosinase activity. Myrosinase activity differed between accessions and cabbage morphotypes, although morphotype tended to have the more significant impact. Savoy cabbage accessions had the highest myrosinase activity, while black kale accessions had the lowest myrosinase activity.

The concentration and profile of GSL and GHP compounds accumulated differed between growing conditions and accessions, within and across cabbage morphotypes. While genetic factors had more influence on the GSL profile of the cabbages, differences in the GSL concentration were more affected by environmental factors during growth, which agrees with previous studies [8]. Growing conditions and cabbage accessions seem to have different effects on GSL and GHP formation, with higher GSL concentrations observed within a growing condition or accession not always resulting in a corresponding greater accumulation of GHPs and vice versa. Results obtained from the study showed that a possible reason for the higher GHP concentrations could be higher myrosinase activities in accessions with lower GSLs, as was observed in white cabbage and black kale accessions. However, this this was not the case in all accessions, suggesting there may be other reasons for the differences obtained. The results obtained therefore suggest that it would be incorrect to assume that higher myrosinase activity and/or GSL accumulation would automatically always result in high concentrations of GHPs.

Variations in the GSL and GHP contents imply differences in the potential healthpromoting and sensory characteristics of the cabbages studied. For example, the high amounts of SFP present in red and white cabbages could potentially provide more health benefits on consumption when compared to other accessions. Conversely, high concentrations of PROG and GN (compounds linked to bitter taste) in wild accessions may reduce consumer acceptance and liking. However, the contents of GSLs and ITCs in B. oleracea vegetables alone does not provide a clear picture of the sensory characteristics of $B$. oleracea vegetables, as other compounds in the plant matrix, such as sugars and sweet tasting amino acids, can influence and modulate the sensory perception of these vegetables, as has been shown in previous studies on Brassicas and other crops such as lettuce [22,94-96].

Field grown cabbages had much higher GSLs and GHPs than glasshouse plants, with a few exceptions (SC-HSC and RC-RD). However, the biggest differences observed were between cabbage morphotypes, irrespective of the conditions under which they were grown. The result of this study suggests that cabbage morphotype and accession might be more important factors for GSL and GHP profiles of plants than the conditions under which they are grown. All individual GSLs and their corresponding GHPs were identified in the accessions studied, and a correlation between GSLs and GHPs was found. The difference in myrosinase activity and GSL and GHP concentrations could not be linked to morphology of head formation (closed heart or open leaf). The influence of growing conditions on cabbage biochemistry will be an important consideration, as the use of highly protected environments for crop production becomes more prevalent through indoor farming, which will also lead to breeding of cabbages with more compact morphology. Our data indicate that protected conditions need to be optimised, possibly by inclusion of controlled abiotic stress, in order to generate the GSL abundance that is observed in field grown crops.

Aliphatic GSLs, nitriles and epithionitriles were the most abundant compounds identified. The results suggest that consumption of raw cabbage may provide limited health 
benefits, as more nitriles and epithionitriles are formed than the more beneficial ITCs. It is therefore recommended to process the cabbages in ways that ensure hydrolysis of GSL to ITCs rather than nitriles. Despite the high amounts of nitriles and epithionitriles formed overall, high amounts of health beneficial SFP were detected in some red and white cabbage accessions. The result suggests that some gene bank accessions can be a good source of beneficial compounds and could be used in breeding programmes to introgress areas of the genome that regulate these compounds from the gene bank accessions into elite commercial cultivars. This can also be helpful for selection of more beneficial accessions for commercial cultivation and production. Given that accessions with lower GSL concentrations and higher myrosinase resulted in high GHP concentrations for some of the accessions studied, breeding programmes should not on only focus on selection of accessions with high GSL concentration but should also consider accessions that have high myrosinase activity and ESM, if maximum conversion of GSLs to ITCs is to be achieved.

Supplementary Materials: The following are available online at https://www.mdpi.com/article/ 10.3390/foods10122903/s1, Figure S1: Cross-section of planted cabbage morphotypes (a) Black kale (b) Wild cabbage (c) Tronchuda cabbage (d) Savoy cabbage (Field grown) (e) Savoy cabbage (Glasshouse grown) (f) Red cabbage (Field grown) (g) Red cabbage (Glasshouse grown) (h) White cabbage (Field grown) (i) White cabbage (Glasshouse grown). Figure S2: Cross-section of cabbages grown under (a) Controlled environment and (b) Glasshouse. Figure S3: Examples of GC-MS chromatograms for field and glasshouse grown samples for each morphotype of cabbage studied (a) Black kale; (b) Wild cabbage; (c) Tronchuda cabbage; (d) Savoy cabbage; (e) Red cabbage; and (f) White cabbage. Table S1: Climatic data of field and glasshouse cabbages. Table S2: Glucosinolate concentration in cabbages grown under different conditions (mg/g DW). Table S3: Glucosinolate hydrolysis products concentration in cabbages grown under different conditions ( $\mu \mathrm{g} / \mathrm{g}$ DW sulforaphane equivalent). Table S4: Pearson correlation matrix table showing correlations between glucosinolates and glucosinolate hydrolysis products identified in cabbage grown under two different conditions (a) correlation coefficients $(r)$ and (b) significance of the correlation ( $p$ value).

Author Contributions: Conceptualization, O.O.O., C.W. and L.M.; methodology, O.O.O., C.W. and L.M.; software, O.O.O., and L.M.; validation, O.O.O., C.W. and L.M.; formal analysis, O.O.O.; investigation, O.O.O.; resources, O.O.O.; data curation, O.O.O.; writing—original draft preparation, O.O.O.; writing-review and editing, O.O.O., C.W. and L.M.; visualization, O.O.O., C.W. and L.M.; supervision, C.W. and L.M.; project administration, O.O.O., C.W. and L.M.; funding acquisition, O.O.O. All authors have read and agreed to the published version of the manuscript.

Funding: This research was funded by the Commonwealth Scholarship commission (CSC), UK, as part of the doctoral research of the first author (O.O.O.), scholar ID: NGCS-2013-363.

Institutional Review Board Statement: Not applicable.

Informed Consent Statement: Not applicable.

Data Availability Statement: The data presented in this study are available on request from the corresponding author.

Acknowledgments: We would like to specially thank Warwick Genetic Bank for providing the cabbage seeds used for the study, Chelsea Snell for her advice on the cabbage growing conditions and Valerie A. Jasper, Tobias James Lane and Matthew J. Richardson of the plant growth unit, University of Reading, for their help with growing the cabbages. A big thank you to Denise Macdonald, Bindukala Radha, Chris Bussey, Josh Stapleford and Charwin Piyapinyo for their help with sample preparation. Our thanks go to Sameer Khalil Ghawi and Olukayode Okunade for support and guidance with myrosinase extraction and assay; Luke Bell, Nicholas Michael, Stella Lignou, Hanis Nadia Yahya and Rashed Alarfaj for support and guidance with glucosinolate extraction and LC-MS analysis; and finally, Salah Abukhabta and Stephen Elmore for help and guidance with glucosinolate hydrolysis product extraction and GC-MS analysis, respectively.

Conflicts of Interest: The authors declare no conflict of interest. The funders had no role in the design of the study; in the collection, analyses, or interpretation of data; in the writing of the manuscript, or in the decision to publish the results. 


\section{References}

1. Plants of the World Online. Available online: http:/ / powo.science.kew.org/taxon/urn:lsid:ipni.org:names:279435-1 (accessed on 24 May 2021).

2. Herr, I.; Buchler, M.W. Dietary constituents of broccoli and other cruciferous vegetables: Implications for prevention and therapy of cancer. Cancer Treat. Rev. 2010, 36, 377-383. [CrossRef] [PubMed]

3. Verkerk, R.; Dekker, M.; Jongen, W.M.F. Post-harvest increase of indolyl glucosinolates in response to chopping and storage of Brassica vegetables. J. Sci. Food Agric. 2001, 81, 953-958. [CrossRef]

4. Guerrero-Beltran, C.E.; Calderon-Oliver, M.; Pedraza-Chaverri, J.; Chirino, Y.I. Protective effect of sulforaphane against oxidative stress: Recent advances. Exp. Toxicol. Pathol. 2012, 64, 503-508. [CrossRef] [PubMed]

5. Mithen, R.F.; Dekker, M.; Verkerk, R.; Rabot, S.; Johnson, I.T. The nutritional significance, biosynthesis and bioavailability of glucosinolates in human foods. J. Sci. Food Agric. 2000, 80, 967-984. [CrossRef]

6. Mithen, R. Glucosinolates-Biochemistry, genetics and biological activity. Plant Growth Regul. 2001, 34, 91-103. [CrossRef]

7. Redovnikovi, I.R.; Gliveti, T.; Delonga, K.; Vorkapi-Fura, J. Glucosinolates and their potential role in plant. Period. Biol. 2008, 110, 297-309.

8. Bjorkman, M.; Klingen, I.; Birch, A.N.E.; Bones, A.M.; Bruce, T.J.A.; Johansen, T.J.; Meadow, R.; Molmann, J.; Seljasen, R.; Smart, L.E.; et al. Phytochemicals of Brassicaceae in plant protection and human health-Influences of climate, environment and agronomic practice. Phytochemistry 2011, 72, 538-556. [CrossRef] [PubMed]

9. Wittstock, U.; Halkier, B.A. Glucosinolate research in the Arabidopsis era. Trends Plant Sci. 2002, 7, 263-270. [CrossRef]

10. Halkier, B.A.; Gershenzon, J. Biology and Biochemistry of Glucosinolates. Annu. Rev. Plant Biol. 2006, 57, 303-333. [CrossRef]

11. Blažević, I.; Montaut, S.; Burčul, F.; Olsen, C.; Burow, M.; Rollin, P.; Agerbirk, N. Glucosinolate structural diversity, identification, chemical synthesis and metabolism in plants. Phytochemistry 2020, 169, 112100. [CrossRef]

12. Bones, A.M.; Rossiter, J.T. The myrosinase-glucosinolate system, its organisation and biochemistry. Physiol. Plant. 1996, 97, 194-208. [CrossRef]

13. Ludikhuyze, L.; Rodrigo, L.; Hendrickx, M. The activity of myrosinase from broccoli (Brassica oleracea L. cv. italica): Influence of intrinsic and extrinsic factors. J. Food Prot. 2000, 63, 400-403. [CrossRef]

14. Morimitsu, Y.; Hayashi, K.; Nakagawa, Y.; Fujii, H.; Horio, F.; Uchida, K.; Osawa, T. Antiplatelet and anticancer isothiocyanates in Japanese domestic horseradish, Wasabi. Mech. Ageing Dev. 2000, 116, 125-134. [CrossRef]

15. Hanschen, F.S.; Lamy, E.; Schreiner, M.; Rohn, S. Reactivity and stability of glucosinolates and their breakdown products in foods. Angew. Chem. Int. Ed. 2014, 53, 11430-11450. [CrossRef] [PubMed]

16. Tsai, S.-C.; Huang, W.-W.; Huang, W.-C.; Lu, C.-C.; Chiang, J.-H.; Peng, S.-F.; Chung, J.-G.; Lin, Y.-H.; Hsu, Y.-M.; Amagaya, S. ERK-modulated intrinsic signaling and G2/M phase arrest contribute to the induction of apoptotic death by allyl isothiocyanate in MDA-MB-468 human breast adenocarcinoma cells. Int. J. Oncol. 2012, 41, 2065-2072. [CrossRef] [PubMed]

17. Leoni, O.; Iori, R.; Palmieri, S.; Esposito, E.; Menegatti, E.; Cortesi, R.; Nastruzzi, C. Myrosinase-generated isothiocyanate from glucosinolates: Isolation, characterization and in vitro antiproliferative studies. Bioorg. Med. Chem. 1997, 5, 1799-1806. [CrossRef]

18. Tripathi, K.; Hussein, U.K.; Anupalli, R.; Barnett, R.; Bachaboina, L.; Scalici, J.; Rocconi, R.P.; Owen, L.B.; Piazza, G.A.; Palle, K. Allyl isothiocyanate induces replication-associated DNA damage response in NSCLC cells and sensitizes to ionizing radiation. Oncotarget 2015, 6, 5237. [CrossRef]

19. Lambrix, V.; Reichelt, M.; Mitchell-Olds, T.; Kliebenstein, D.J.; Gershenzon, J. The Arabidopsis Epithiospecifier Protein Promotes the Hydrolysis of Glucosinolates to Nitriles and Influences Trichoplusia ni Herbivory. Plant Cell 2001, 13, 2793-2807. [CrossRef]

20. Baik, H.Y.; Juvik, J.; Jeffery, E.H.; Wallig, M.A.; Kushad, M.; Klein, B.P. Relating glucosinolate content and flavor of broccoli cultivars. J. Food Sci. 2003, 68, 1043-1050. [CrossRef]

21. Cox, D.N.; Melo, L.; Zabaras, D.; Delahunty, C.M. Acceptance of health-promoting Brassica vegetables: The influence of taste perception, information and attitudes. Public Health Nutr. 2012, 15, 1474-1482. [CrossRef]

22. Beck, T.K.; Jensen, S.; Bjoern, G.K.; Kidmose, U. The Masking Effect of Sucrose on Perception of Bitter Compounds in Brassica Vegetables. J. Sens. Stud. 2014, 29, 190-200. [CrossRef]

23. Doorn, H.E.v.; Kruk, G.C.v.d.; Holst, G.-J.v.; Raaijmakers-Ruijs, N.C.; Postma, E.; Groeneweg, B.; Jongen, W.H.F. The Glucosinolates Sinigrin and Progoitrin are important determination for taste. J. Sci. Food Agric. 1998, 78, 30-38. [CrossRef]

24. Wei, J.; Miao, H.; Wang, Q. Effect of glucose on glucosinolates, antioxidants and metabolic enzymes in Brassica sprouts. Sci. Hortic. 2011, 129, 535-540. [CrossRef]

25. Charron, C.S.; Saxton, A.M.; Sams, C.E. Relationship of climate and genotype to seasonal variation in the glucosinolate-myrosinase system. II. Myrosinase activity in ten cultivars of Brassica oleracea grown in fall and spring seasons. J. Sci. Food Agric. 2005 85, 682-690. [CrossRef]

26. Charron, C.S.; Sams, C.E. Glucosinolate content and myrosinase activity in rapid-cycling Brassica oleracea grown in a controlled environment. J. Am. Soc. Hort. Sci. 2004, 129, 321-330. [CrossRef]

27. Rosa, E.A.; Rodrigues, P.M. The effect of light and temperature on glucosinolate concentration in the leaves and roots of cabbage seedlings. J. Sci. Food Agric. 1998, 78, 208-212. [CrossRef]

28. Yen, G.-C.; Wei, Q.-K. Myrosinase activity and total glucosinolate content of cruciferous vegetables, and some properties of cabbage myrosinase in Taiwan. J. Sci. Food Agric. 1993, 61, 471-475. [CrossRef] 
29. Penas, E.; Frias, J.; Martinez-Villaluenga, C.; Vidal-Valverde, C. Bioactive compounds, myrosinase activity, and antioxidant capacity of white cabbages grown in different locations of Spain. J. Agric. Food Chem. 2011, 59, 3772-3779. [CrossRef]

30. Farnham, M.W.; Wilson, P.E.; Stephenson, K.K.; Fahey, J.W. Genetic and environmental effects on glucosinolate content and chemoprotective potency of broccoli. Plant Breed. 2004, 123, 60-65. [CrossRef]

31. Verkerk, R.; Schreiner, M.; Krumbein, A.; Ciska, E.; Holst, B.; Rowland, I.; Schrijver, R.D.; Hansen, M.; Gerhaeuser, G.; Mithen, R.; et al. Glucosinolates in Brassica vegetables: The influence of the food supply chain on intake, bioavailability and human health. Mol. Nutr. Food Res. 2009, 53, S219. [CrossRef] [PubMed]

32. Velasco, P.; Cartea, M.E.; González, C.; Vilar, M.; Ordás, A. Factors affecting the glucosinolate content of kale (Brassica oleracea acephala group). J. Agric. Food Chem. 2007, 55, 955-962. [CrossRef]

33. Steindal, A.L.H.; Rødven, R.; Hansen, E.; Mølmann, J. Effects of photoperiod, growth temperature and cold acclimatisation on glucosinolates, sugars and fatty acids in kale. Food Chem. 2015, 174, 44-51. [CrossRef] [PubMed]

34. Rungapamestry, V.; Duncan, A.J.; Fuller, Z.; Ratcliffe, B. Changes in glucosinolate concentrations, myrosinase activity, and production of metabolites of glucosinolates in cabbage (Brassica oleracea var. capitata) cooked for different durations. J. Agric. Food Chem. 2006, 54, 7628-7634. [CrossRef] [PubMed]

35. Rungapamestry, V.; Duncan, A.J.; Fuller, Z.; Ratcliffe, B. Influence of blanching and freezing broccoli (Brassica oleracea var. italica) prior to storage and cooking on glucosinolate concentrations and myrosinase activity. Eur. Food Res. Technol. $2008,227,37$.

36. Ghawi, S.K.; Methven, L.; Rastall, R.A.; Niranjan, K. Thermal and high hydrostatic pressure inactivation of myrosinase from green cabbage: A kinetic study. Food Chem. 2012, 131, 1240-1247. [CrossRef]

37. Okunade, O.A.; Methven, L.; Niranjan, K. A comparison of myrosinase activity and stability in fresh broccoli (B. oleracea var. italica) and Brown Mustard (B. juncea) Seeds. Turk. J. Agric.-Food Sci. Technol. 2020, 8, 64. [CrossRef]

38. Singh, J.; Rai, M.; Upadhyay, A.K.; Prasad, K. Sinigrin (2-propenyl glucosinolate) content and myrosinase activity in Brassica vegetables. Int. J. Veg. Sci. 2007, 13, 21-31. [CrossRef]

39. Charron, C.S.; Saxton, A.M.; Sams, C.E. Relationship of climate and genotype to seasonal variation in the glucosinolate-myrosinase system. I. Glucosinolate content in ten cultivars of Brassica oleracea grown in fall and spring seasons. J. Sci. Food Agric. 2005, 85, 671-681. [CrossRef]

40. Cartea, M.E.; Velasco, P.; Obregon, S.; Padilla, G.; de Haro, A. Seasonal variation in glucosinolate content in Brassica oleracea crops grown in northwestern Spain. Phytochemistry 2008, 69, 403-410. [CrossRef]

41. Ciska, E.; Martyniak-Przybyszewska, B.; Kozlowska, H. Content of glucosinolates in cruciferous vegetables grown at the same site for two years under different climatic conditions. J. Agric. Food Chem. 2000, 48, 2862-2867. [CrossRef]

42. Jasper, J.; Wagstaff, C.; Bell, L. Growth temperature influences postharvest glucosinolate concentrations and hydrolysis product formation in first and second cuts of rocket salad. Postharvest Biol. Technol. 2020, 163, 111157. [CrossRef] [PubMed]

43. Hanschen, F.S.; Schreiner, M. Isothiocyanates, nitriles, and epithionitriles from glucosinolates are affected by genotype and developmental stage in Brassica oleracea varieties. Front. Plant Sci. 2017, 8, 1095. [CrossRef] [PubMed]

44. Daxenbichler, M.E.; Van Etten, C.H.; Spencer, G.F. Glucosinolates and derived products in cruciferous vegetables. Identification of organic nitriles from cabbage. J. Agric. Food Chem. 1977, 25, 121-124. [CrossRef]

45. Van Eylen, D.; Bellostas, N.; Strobel, B.W.; Oey, I.; Hendrickx, M.; Van Loey, A.; Sørensen, H.; Sørensen, J.C. Influence of pressure/temperature treatments on glucosinolate conversion in broccoli (Brassica oleraceae L. cv Italica) heads. Food Chem. 2009, 112, 646-653. [CrossRef]

46. Church, A.; Mitchell, R.; Ravenscroft, N.; Stapleton, L.M. 'Growing your own': A multi-level modelling approach to understanding personal food growing trends and motivations in Europe. Ecol. Econ. 2015, 110, 71-80. [CrossRef]

47. Tolstrup, J. The Rise of the Indoor Gardening Movement. Available online: https://blog.backtotheroots.com/2018/03/14/riseindoor-gardening-movement/ (accessed on 25 May 2021).

48. Ghawi, S.K.; Methven, L.; Niranjan, K. The potential to intensify sulforaphane formation in cooked broccoli (Brassica oleracea var. italica) using mustard seeds (Sinapis alba). Food Chem. 2013, 138, 1734-1741. [CrossRef]

49. Gatfield, I.L.; Sand, T. A coupled enzymatic procedure for the determination of myrosinase activity. Lebensm.-Wiss. Technol. 1983, 16, 73-75.

50. Wilkinson, A.P.; Rhodes, M.J.C.; Fenwick, R.G. Myrosinase Activity of Cruciferous Vegetables. J. Sci. Food Agric. 1984, 35, 543-552. [CrossRef]

51. Bradford, M.M. A rapid and sensitive method for the quantitation of microgram quantities of protein utilizing the principle of protein-dye binding. Anal. Biochem. 1976, 72, 248-254. [CrossRef]

52. Bell, L.; Oruna-Concha, M.J.; Wagstaff, C. Identification and quantification of glucosinolate and flavonol compounds in rocket salad (Eruca sativa, Eruca vesicaria and Diplotaxis tenuifolia) by LC-MS: Highlighting the potential for improving nutritional value of rocket crops. Food Chem. 2015, 172, 852-861. [CrossRef]

53. Clarke, D.B. Glucosinolates, structures and analysis in food. Anal. Methods 2010, 2, 310. [CrossRef]

54. Rochfort, S.J.; Trenerry, V.C.; Imsic, M.; Panozzo, J.; Jones, R. Class targeted metabolomics: ESI ion trap screening methods for glucosinolates based on MSn fragmentation. Phytochemistry 2008, 69, 1671-1679. [CrossRef] [PubMed]

55. Lelario, F.; Bianco, G.; Bufo, S.A.; Cataldi, T.R.I. Establishing the occurrence of major and minor glucosinolates in Brassicaceae by LC-ESI-hybrid linear ion-trap and Fourier-transform ion cyclotron resonance mass spectrometry. Phytochemistry 2012, 73, 74-83. [CrossRef] 
56. Bennett, R.N.; Mellon, F.A.; Kroon, P.A. Screening crucifer seeds as sources of specific intact glucosinolates using ion-pair high-performance liquid chromatography negative ion electrospray mass spectrometry. J. Agric. Food Chem. 2004, 52, 428-438. [CrossRef]

57. Bell, L.; Yahya, H.N.; Oloyede, O.O.; Methven, L.; Wagstaff, C. Changes in rocket salad phytochemicals within the commercial supply chain: Glucosinolates, isothiocyanates, amino acids and bacterial load increase significantly after processing. Food Chem. 2017, 221, 521-534. [CrossRef]

58. Al-Gendy, A.A.; Lockwood, G.B. GC-MS analysis of volatile hydrolysis products from glucosinolates in Farsetia aegyptia var. ovalis. Flavour Fragr. J. 2003, 18, 148-152. [CrossRef]

59. Arora, R.; Sharma, D.; Kumar, R.; Singh, B.; Vig, A.P.; Arora, S. Evaluating extraction conditions of glucosinolate hydrolytic products from seeds of Eruca sativa (Mill.) Thell. using GC-MS. J. Food Sci. 2014, 79, C1964-C1969. [CrossRef]

60. Hong, E.; Kim, G.-H. GC-MS analysis of the extracts from Korean cabbage (Brassica campestris L. ssp. pekinensis) and its seed. Prev. Nutr. Food Sci. 2013, 18, 218-221. [CrossRef]

61. Spencer, G.F.; Daxenbichler, M.E. Gas chromatography-mass spectrometry of nitriles, isothiocyanates and oxazolidinethiones derived from cruciferous glucosinolates. J. Sci. Food Agric. 1980, 31, 359-367. [CrossRef]

62. Hanschen, F.S.; Klopsch, R.; Oliviero, T.; Schreiner, M.; Verkerk, R.; Dekker, M. Optimizing isothiocyanate formation during enzymatic glucosinolate breakdown by adjusting $\mathrm{pH}$ value, temperature and dilution in Brassica vegetables and Arabidopsis thaliana. Sci. Rep. 2017, 7, 40807. [CrossRef]

63. de Pinho, P.G.; Valentão, P.; Gonçalves, R.F.; Sousa, C.; Andrade, P.B. Volatile composition of Brassica oleracea L. var. costata DC leaves using solid-phase microextraction and gas chromatography/ion trap mass spectrometry. Rapid Commun. Mass Spectrom. 2009, 23, 2292-2300. [CrossRef] [PubMed]

64. Vaughn, S.F.; Palmquist, D.E.; Duval, S.M.; Berhow, M.A. Herbicidal activity of glucosinolate-containing seedmeals. Weed Sci. 2017, 54, 743-748. [CrossRef]

65. Travers-Martin, N.; Kuhlmann, F.; Muller, C. Revised determination of free and complexed myrosinase activities in plant extracts. Plant Physiol. Biochem. 2008, 46, 506-516. [CrossRef] [PubMed]

66. Grace, J. 3. Plant response to wind. Agric. Ecosyst. Environ. 1988, 22-23, 71-88. [CrossRef]

67. Hirai, M.Y.; Yano, M.; Goodenowe, D.B.; Kanaya, S.; Kimura, T.; Awazuhara, M.; Arita, M.; Fujiwara, T.; Saito, K. Integration of transcriptomics and metabolomics for understanding of global responses to nutritional stresses in Arabidopsis thaliana. Proc. Natl. Acad. Sci. USA 2004, 101, 10205-10210. [CrossRef]

68. Yuan, G.; Wang, X.; Guo, R.; Wang, Q. Effect of salt stress on phenolic compounds, glucosinolates, myrosinase and antioxidant activity in radish sprouts. Food Chem. 2010, 121, 1014-1019. [CrossRef]

69. Rodríguez-Hernández, M.D.C.; Moreno, D.A.; Carvajal, M.; Martínez-Ballesta, M.D.C. Genotype influences sulfur metabolism in broccoli (Brassica oleracea L.) under elevated CO2 and NaCl stress. Plant Cell Physiol. 2014, 55, 2047-2059. [CrossRef] [PubMed]

70. Pang, Q.; Guo, J.; Chen, S.; Chen, Y.; Zhang, L.; Fei, M.; Jin, S.; Li, M.; Wang, Y.; Yan, X. Effect of salt treatment on the glucosinolate-myrosinase system in Thellungiella salsuginea. Plant Soil 2012, 355, 363-374. [CrossRef]

71. Kissen, R.; Eberl, F.; Winge, P.; Uleberg, E.; Martinussen, I.; Bones, A.M. Effect of growth temperature on glucosinolate profiles in Arabidopsis thaliana accessions. Phytochemistry 2016, 130, 106-118. [CrossRef]

72. Koh, J.; Chen, G.; Yoo, M.-J.; Zhu, N.; Dufresne, D.; Erickson, J.E.; Shao, H.; Chen, S. Comparative proteomic analysis of Brassica napus in response to drought stress. J. Proteome Res. 2015, 14, 3068-3081. [CrossRef]

73. Rosa, E.; Heaney, R. Seasonal variation in protein, mineral and glucosinolate composition of Portuguese cabbages and kale. Anim. Feed Sci. Technol. 1996, 57, 111-127. [CrossRef]

74. Kushad, M.M.; Brown, A.F.; Kurilich, A.C.; Juvik, J.A.; Klein, B.P.; Wallig, M.A.; Jeffery, E.H. Variation of glucosinolates in vegetable crops of Brassica oleracea. J. Agric. Food Chem. 1999, 47, 1541-1548. [CrossRef]

75. Park, S.; Arasu, M.V.; Lee, M.-K.; Chun, J.-H.; Seo, J.M.; Al-Dhabi, N.A.; Kim, S.-J. Analysis and metabolite profiling of glucosinolates, anthocyanins and free amino acids in inbred lines of green and red cabbage (Brassica oleracea L.). LWT-Food Sci. Technol. 2014, 58, 203-213. [CrossRef]

76. Zabaras, D.; Roohani, M.; Krishnamurthy, R.; Cochet, M.; Delahunty, C.M. Characterisation of taste-active extracts from raw Brassica oleracea vegetables. Food Funct. 2013, 4, 592-601. [CrossRef]

77. Fahey, J.W.; Zalcmann, A.T.; Talalay, P. The chemical diversity and distribution of glucosinolates and isothiocyanates among plants. Phytochemistry 2001, 56, 5-51. [CrossRef]

78. Song, L.; Thornalley, P.J. Effect of storage, processing and cooking on glucosinolate content of Brassica vegetables. Food Chem. Toxicol. 2007, 45, 216-224. [CrossRef]

79. Drewnowski, A.; Gomez-Carneros, C. Bitter taste, phytonutrients, and the consumer: A review. Am. J. Clin. Nutr. 2000, 72, 1424-1435. [CrossRef]

80. Vaughn, S.F.; Berhow, M.A. Glucosinolate hydrolysis products from various plant sources: PH effects, isolation, and purification. Ind. Crop. Prod. 2005, 21, 193-202. [CrossRef]

81. Rohr, F.; Ulrichs, C.; Mucha-Pelzer, T.; Mewis, I. Variability of aliphatic glucosinolates in Arabidopsis and their influence on insect resistance. Commun. Agric. Appl. Biol. Sci. 2006, 71, 507-515. [PubMed]

82. Wurr, D.C.E.; Fellows, J.R.; Phelps, K. Investigating trends in vegetable crop response to increasing temperature associated with climate change. Sci. Hortic. 1996, 66, 255-263. [CrossRef] 
83. Gigolashvili, T.; Berger, B.; Flügge, U.-I. Specific and coordinated control of indolic and aliphatic glucosinolate biosynthesis by R2R3-MYB transcription factors in Arabidopsis thaliana. Phytochem. Rev. 2009, 8, 3-13. [CrossRef]

84. Zhao, F.; Evans, E.J.; Bilsborrow, P.E.; Syers, J.K. Influence of nitrogen and sulphur on the glucosinolate profile of rapeseed (Brassica napus L). J. Sci. Food Agric. 1994, 64, 295-304. [CrossRef]

85. Burow, M.; Wittstock, U. Regulation and function of specifier proteins in plants. Phytochem. Rev. 2009, 8, 87-99. [CrossRef]

86. Angelino, D.; Jeffery, E. Glucosinolate hydrolysis and bioavailability of resulting isothiocyanates: Focus on glucoraphanin. $J$. Funct. Foods 2014, 7, 67-76. [CrossRef]

87. Fenwick, G.R.; Griffiths, N.M.; Heaney, R.K. Bitterness in brussels sprouts (Brassica oleracea L. var.gemmifera): The role of glucosinolates and their breakdown products. J. Sci. Food Agric. 1983, 34, 73-80. [CrossRef]

88. Traka, M.H.; Saha, S.; Huseby, S.; Kopriva, S.; Walley, P.G.; Barker, G.C.; Moore, J.; Mero, G.; van den Bosch, F.; Constant, H.; et al. Genetic regulation of glucoraphanin accumulation in Beneforté broccoli. New Phytol. 2013, 198, 1085-1095. [CrossRef]

89. James, D.C.; Rossiter, J.T. Development and characteristics of myrosinase in Brassica napus during early seedling growth. Physiol. Plant. 1991, 82, 163-170. [CrossRef]

90. Klopsch, R.; Witzel, K.; Börner, A.; Schreiner, M.; Hanschen, F.S. Metabolic profiling of glucosinolates and their hydrolysis products in a germplasm collection of Brassica rapa turnips. Food Res. Int. 2017, 100, 392-403. [CrossRef]

91. Bell, L.; Kitsopanou, E.; Oloyede, O.O.; Lignou, S. Important odorants of four Brassicaceae species, and discrepancies between glucosinolate profiles and observed hydrolysis products. Foods 2021, 10, 1055. [CrossRef] [PubMed]

92. Matusheski, N.V.; Swarup, R.; Juvik, J.A.; Mithen, R.; Bennett, M.; Jeffery, E.H. Epithiospecifier protein from broccoli (Brassica oleracea L. ssp. italica) inhibits formation of the anticancer agent sulforaphane. J. Agric. Food Chem. 2006, 54, 2069-2076. [CrossRef] [PubMed]

93. Winkler, S.; Faragher, J.; Franz, P.; Imsic, M.; Jones, R. Glucoraphanin and flavonoid levels remain stable during simulated transport and marketing of broccoli (Brassica oleracea var. italica) heads. Postharvest Biol. Technol. 2007, 43, 89-94. [CrossRef]

94. Jones, R.B.; Faragher, J.D.; Winkler, S. A review of the influence of postharvest treatments on quality and glucosinolate content in broccoli (Brassica oleracea var. italica) heads. Postharvest Biol. Technol. 2006, 41, 1-8. [CrossRef]

95. van Doorn, J.E. Development of Vegetables with Improved Consumer Quality: A Case Study in Brussels Sprouts; University of Wageningen: Wageningen, The Netherlands, 1999.

96. Chadwick, M.; Gawthrop, F.; Michelmore, R.W.; Wagstaff, C.; Methven, L. Perception of bitterness, sweetness and liking of different genotypes of lettuce. Food Chem. 2016, 197, 66-74. [CrossRef] [PubMed] 